\title{
Acute Ethanol Exposure Increases the Susceptibility of the Donor Hearts to Ischemia/Reperfusion Injury after Transplantation in Rats
}

\author{
Shiliang $\mathrm{Li}^{1,49}$, Sevil Korkmaz ${ }^{1 * 9}$, Sivakkanan Loganathan ${ }^{1}$, Alexander Weymann ${ }^{1}$, Tamás Radovits $^{2}$, \\ Enikö Barnuczz, ${ }^{1,}$ Kristóf Hirschberg ${ }^{1}$, Peter Hegedüs ${ }^{1,2}$, Yan Zhou ${ }^{5}$, Liang Tao ${ }^{6}$, Szabolcs Páli ${ }^{1,2}$, \\ Gábor Veres ${ }^{1,3}$, Matthias Karck', Gábor Szabó'
}

1 Department of Cardiac Surgery, University of Heidelberg, Heidelberg, Germany, 2 Heart Center, Semmelweis University, Budapest, Hungary, 3 Department of Cardiac Surgery, Semmelweis University, Budapest, Hungary, 4 Department of Cardiovascular Surgery, Union Hospital, Tongji Medical College, Huazhong University of Science and Technology, Wuhan, China, $\mathbf{5}$ Department of Otolaryngology, Union Hospital of Tongji Medical College, Hua-Zhong University of Science and Technology, Wuhan, China, 6 Department of Cardiac Surgery, Wuhan Asia Heart Hospital, Wuhan, China

\begin{abstract}
Background: Many donor organs come from youths involved in alcohol-related accidental death. The use of cardiac allografts for transplantation from donors after acute poisoning is still under discussion while acute ethanol intoxication is associated with myocardial functional and morphological changes. The aims of this work were 1) to evaluate in rats the time-course cardiac effects of acute ethanol-exposure and 2) to explore how its abuse by donors might affect recipients in cardiac pump function after transplantation.

Methods: Rats received saline or ethanol $(3.45 \mathrm{~g} / \mathrm{kg}$, ip). We evaluated both the mechanical and electrical aspects of cardiac function $1 \mathrm{~h}, 6 \mathrm{~h}$ or $24 \mathrm{~h}$ after injection. Plasma cardiac troponin-T and glucose-levels were measured and histological examination of the myocardium was performed. In addition, heart transplantation was performed, in which donors received ethanol $6 \mathrm{~h}$ or $24 \mathrm{~h}$ prior to explantation. Graft function was measured $1 \mathrm{~h}$ or $24 \mathrm{~h}$ after transplantation. Myocardial TBARSconcentration was measured; mRNA and protein expression was assessed by quantitative real-time PCR and Western blot, respectively.

Results: Ethanol administration resulted in decreased load-dependent ( $-34 \pm 9 \%)$ and load-independent $(-33 \pm 12 \%)$ contractility parameters, LV end-diastolic pressure and elevated blood glucose levels at $1 \mathrm{~h}$, which were reversed to the level of controls after $6 \mathrm{~h}$ and $24 \mathrm{~h}$. In contrast to systolic dysfunction, active relaxation and passive stiffness are slowly recovered or sustained during $24 \mathrm{~h}$. Moreover, troponin-T-levels were increased at $1 \mathrm{~h}, 6 \mathrm{~h}$ and $24 \mathrm{~h}$ after ethanol injection. ST-segment elevation $(+47 \pm 10 \%)$, elongated QT-interval $(+38 \pm 4 \%)$, enlarged cardiomyocyte, DNA-strand breaks, increased both mRNA and protein levels of superoxide dismutase-1, glutathione peroxydase-4, cytochrome-c-oxidase and metalloproteinase- 9 were observed $24 \mathrm{~h}$ following ethanol-exposure. After heart transplantation, decreased myocardial contractility and relaxation, oxidative stress and altered protein expression were observed.

Conclusions: These results demonstrate acute alcohol abuse increases the susceptibility of donor hearts to ischemia/ reperfusion in a rat heart transplant model even though the global contractile function recovers $6 \mathrm{~h}$ after ethanoladministration.
\end{abstract}

Citation: Li S, Korkmaz S, Loganathan S, Weymann A, Radovits T, et al. (2012) Acute Ethanol Exposure Increases the Susceptibility of the Donor Hearts to Ischemia/Reperfusion Injury after Transplantation in Rats. PLoS ONE 7(11): e49237. doi:10.1371/journal.pone.0049237

Editor: Xiongwen Chen, Temple University, United States of America

Received March 22, 2012; Accepted October 7, 2012; Published November 14, 2012

Copyright: $\odot 2012 \mathrm{Li}$ et al. This is an open-access article distributed under the terms of the Creative Commons Attribution License, which permits unrestricted use, distribution, and reproduction in any medium, provided the original author and source are credited.

Funding: This study was supported by the Land Baden-Württemberg, Germany, by the Medical Faculty of the University of Heidelberg, Germany (to Dr. S. Korkmaz and Dr. K. Hirschberg), and by the János Bolyai Research Scholarship of the Hungarian Academy of Sciences (to T. Radovits). The funders had no role in study design, data collection and analysis, decision to publish, or preparation of the manuscript.

Competing Interests: The authors have declared that no competing interests exist.

*E-mail: korkmaz@uni-heidelberg.de

9 These authors contributed equally to this work.

\section{Introduction}

Episodic excessive alcohol consumption commonly referred to as "binge drinking" is common cause of accidental death, violent behaviour as well as suicide, and may be associated with compromised myocardial contractility [1], cardiac arrhythmias, most frequently atrial fibrillation [2] and sudden death [3]. The mechanisms of alcoholic cardiomyopathy, including a) direct cardiotoxicity of ethanol and its major metabolite acetaldehyde, specifically inducing ischemia [4], b) increased production of reactive oxygen species such as hydrogen peroxide [5], c) disturbance in the intracellular calcium homeostasis [6], d) 
accumulation of fatty acid ethyl esters [7] and e) impaired mitochondrial function may be precipitating events.

Currently, donors with a history of alcohol abuse, accounting for about $1 / 5^{\text {th }}$ of all donors, are routinely accepted, despite existing evidence supporting the potential deleterious effect of donors' alcohol consumption on recipients' survival and higher rejection rate [8]. Many donor organs come from youths involved in alcohol-related accidental falls, fatal car crashes and suicidal behaviour. Although the success of heart transplantation is highly influenced by good donor selection, the use of cardiac allografts for transplantation from donors after acute poisoning is still under discussion due to potential toxic organ injuries and secondary toxic effects in recipients [9]. Previously some studies have been conducted to evaluate the acute hemodynamic effects of alcohol ingestion in mice, rats and guinea pigs $[10,11]$. To our knowledge, in a rat model of potential organ donor, no detailed characterization of the left-ventricular (LV) systolic and diastolic function at various time intervals up to $24 \mathrm{~h}$ after alcohol intoxication has been performed in vivo using a pressure-volume conductance catheter. Moreover, despite much having been published about the pathogenesis of alcohol intake, molecular mechanisms on the time-course of ethanol-induced cardiac dysfunction are limited. Therefore, the aim of this work was to evaluate the time-course cardiac effects of acute ethanol-exposure and the possible mechanism(s) of action involved in a model of a potential organ donor. In addition, using experimental rat cardiac transplantation, we sought to explore how acute alcohol abuse in donors might affect recipients' cardiac pump function in the early phase after transplantation. This technique includes both reperfusion with blood in an intact animal, simulating the clinical setting, and robust assessment of LV function.

\section{Materials and Methods}

\section{Animals and Ethics Statement}

Male Lewis rats (250 to $350 \mathrm{~g}$; Charles River, Sulzfeld, Germany) were housed in a room at $22 \pm 2{ }^{\circ} \mathrm{C}$ under 12-h light/ dark cycles and were fed a standard laboratory rat diet and water ad libitum. The rats were acclimatized for at least 1 week before experiments and were randomly assigned to different groups. All animals received humane care in compliance with the Principles of Laboratory Animal Care formulated by the National Society for Medical Research and the Guide for the Care and Use of Laboratory Animals prepared by the Institute of Laboratory Animal Resources and published by the National Institutes of Health (NIH Publication No. 86-23, revised 1996). This investigation was reviewed and approved by the ethical committee for animal experimentation at Semmelweis University and by the Hungarian government authorities (22.1/2674/3/2011).

\section{Acute ethanol intoxication}

Experimental animals. The experimental procedure involved intraperitoneal injections $(1 \mathrm{ml} / 100 \mathrm{~g}$ body weight $)$ with either saline $(0.9 \% \mathrm{NaCl})$ or alcohol. The dose was $3.45 \mathrm{~g} / \mathrm{kg}$ $(75 \mathrm{mmol} / \mathrm{kg}$ ) body weight for ethanol. Controls were injected with identical volume of saline.

Rats $(\mathrm{n}=74)$ were randomly divided into the following groups: (1) control groups received saline and were euthanized $1 \mathrm{~h}, 6 \mathrm{~h}$ or $24 \mathrm{~h}$ after saline injection respectively; (2) ethanol-1 h group (3) ethanol-6 $\mathrm{h}$ group and (4) ethanol-24 $\mathrm{h}$ group received ethanol and were euthanized $1 \mathrm{~h}, 6 \mathrm{~h}$ or $24 \mathrm{~h}$ after ethanol dosing, respectively. We found no difference between the groups receiving saline at different time points with any of the parameters measured and thus combined the values.
Electrocardiography. Rats were anesthetized with sodium pentobarbital $(60 \mathrm{mg} / \mathrm{kg}$, i.p.) and kept in a supine position on heating pads maintaining their core temperature (measured via a rectal probe) at $37^{\circ} \mathrm{C}$. Standard 12-lead electrocardiograms were recorded using needle electrodes placed subcutaneously in each fore leg and hind legs, and six around the chest. All leads were connected to a standard direct-writing recorder (Mortara Instrument, WI, USA). The paper speed was set at $50 \mathrm{~mm} / \mathrm{sec}$ and the sensitivity at $10 \mathrm{~mm} / \mathrm{mV}$. ST-segment elevation and the length of the QT-interval measured in lead-II were the focuses of electrocardiographical analysis. The QT interval was defined as the segment from the onset of the QRS complex to the end of the $\mathrm{T}$ wave, defined as the intersection point with the isoelectric line. QT interval was corrected using normalized Bazett's formula adjusted for rats $\left(\mathrm{nQTc}=\mathrm{QT} /(\mathrm{RR} / \mathrm{f})^{1 / 2}\right)$ [12]. Electrocardiography was analyzed by an investigator unaware of treatment attribution of the animals.

Hemodynamic measurements. Rats were placed on controlled heating pads, core temperature was measured via a rectal probe and was maintained at $37^{\circ} \mathrm{C}$, tracheotomized, intubated and artificially ventilated. To assess cardiac function, LV pressurevolume analysis was performed with a $2 \mathrm{~F}$ pressure-volume conductance catheter (SPR-838, Millar Instruments, Houston, TX, USA). With the special pressure-volume analysis program (PVAN, Millar Instruments, Houston, TX, USA), heart rate, systolic and diastolic blood pressures, mean arterial pressure, LV end-systolic pressure, LV end-diastolic pressure, maximal slope of the systolic pressure increment $\left(\mathrm{dP} / \mathrm{dt}_{\max }\right)$, maximal slope of the diastolic pressure decrement $\left(\mathrm{dP} / \mathrm{dt}_{\mathrm{min}}\right)$ as load dependent hemodynamic parameters were calculated. LV pressure-volume relations were measured by transiently occluding the inferior vena cava (reducing preload) under the diaphragm with a cotton-tipped applicator. The slope of $\mathrm{dP} / \mathrm{dt}_{\max } /$ end-diastolic volume $(\mathrm{dP} /$ $\mathrm{dt}_{\max } / \mathrm{EDV}$ ) relationship was calculated as load independent index of LV contractility. The slope of the end-diastolic pressure-volume relationship (EDPVR) was calculated as a reliable index of $\mathrm{LV}$ stiffness.

At the end of each experiment, $0.1 \mathrm{ml}$ hypertonic saline was injected into the jugular vein, and from the shift of pressurevolume relations parallel conductance volume was calculated by pressure-volume analysis software (PVAN, Millar Instruments, Houston, TX, USA) and used for correction for cardiac mass volume. After completing the hemodynamic measurements, blood samples were collected from the inferior vena cava. The volume calibration of the conductance system was performed as described previously [13]. Nine cylindrical holes in a block $1 \mathrm{~cm}$ deep and with known diameter ranging from 2 to $11 \mathrm{~mm}$ were filled with fresh heparinized rat blood. The linear volume-conductance regression of the absolute volume in each cylinder in comparison to the raw signal acquired by the conductance catheter was used as the volume calibration formula.

Biochemical measurements. Blood collected from the rats in lithium with heparin and gel tubes (S-Monovette ${ }^{\circledR}$, Sarstedt, Nümbrecht, Germany) was immediately centrifuged and plasma was separated. Levels of plasma cardiac troponin- $T$ and glucose were determined.

Histological examination. Hearts from rats in each experimental group were fixed in buffered paraformaldehyde solution $(4 \%)$ and embedded in paraffin. Then, $5-\mu \mathrm{m}$ thick sections were placed on adhesive slides and stained with hematoxylin and eosin (H\&E). Cardiomyocyte cross-sectional areas were calculated on a microscope $(\times 400)$ using the Cell $\wedge$ A software (Olympus Soft Imaging Solutions GmbH, Germany). Histological evaluation was 
conducted by an investigator unaware of treatment attribution of the animals.

Gardiac troponin I immunofluorescence- and Terminal deoxynucleotidyl transferase-mediated dUTP nick endlabeling (TUNEL) stainings. For identification of cardiomyocytes, immunohistochemical staining for cardiac troponin I has been performed. Sections were de-paraffinized with xylene and passaged through decreasing concentrations of ethanol, washed with distilled water and heated with Tris- ethylenediaminetetraacetic acid (EDTA) buffer $(\mathrm{pH}=9)$ for $30 \mathrm{~min}$ to retrieve antigenic epitopes. Then, sections were washed with phosphate buffer saline $(\mathrm{PBS}, 1 \times)$ for $3 \times 5 \mathrm{~min}$. After permeabilization by $0.3 \%$ Triton $\mathrm{X}$ 100 for $10 \mathrm{~min}$ and blocking with $1 \%$ bovine serum albumin (BSA) and $0.1 \%$ Triton $\mathrm{X}-100$, sections were incubated at room temperature for $1 \mathrm{~h}$ with the primary rabbit polyclonal antibodies directed against troponin-I (1:200, Abcam, Cambridge, UK). The incubation with undiluted FITC-conjugated goat anti-rabbit IgG polyclonal secondary antibody (Abcam, Cambridge, UK) was at $37^{\circ} \mathrm{C}$ for $30 \mathrm{~min}$. After washing with PBS $(1 \times)$ for $3 \times 5 \mathrm{~min}$, the sections were incubated with $50 \mu$ l of Terminal deoxynucleotidyl Transferase (TdT) enzyme and TUNEL Reaction mixture for $1 \mathrm{~h}$ at $37^{\circ} \mathrm{C}$ in the dark (Roche Diagnostics, Mannheim, Germany). The sections were then washed with PBS $(1 \times)$ for $3 \times 5 \mathrm{~min}$. The slides were mounted using 4', 6-diamidino-2-phenylindole (DAPI)Fluoromount-G ${ }^{\text {TM }}$ (SouthernBiotech, Birmingham, USA), covered with cover glass and analyzed under a fluorescence microscope. The number of TUNEL-positive cells was expressed as the ratio of DAPI-TUNEL double-labeled nuclei to the total number of nuclei stained with DAPI. Cells were counted in four fields characterizing each specimen), and an average value was calculated for each experimental group. The evaluation was conducted by an investigator blinded to the experimental groups.

Quantitative real-time polymerase chain reactions (PCR). Total RNA was isolated from the hearts with the RNeasy Fibrous Tissue Mini Kit (Qiagen, Hilden, Germany). RNA concentration and purity were determined photometrically $(230 \mathrm{~nm}, 260 \mathrm{~nm}$ and $280 \mathrm{~nm})$. Reverse transcription was performed with the QuantiTect Reverse Transcription Kit (Qiagen) using $800 \mathrm{ng}$ RNA in a total volume of $20 \mu \mathrm{l}$. Quantitative real-time PCR was performed with the LightCycler480 system using the LightCycler480 Probes Master and Universal ProbeLibrary probes (Roche, Mannheim, Germany). The conditions for PCR were as follows: $95^{\circ} \mathrm{C}$ for $10 \mathrm{~min}$ (1cycle), $95^{\circ} \mathrm{C}$ for $10 \mathrm{~s}, 60^{\circ} \mathrm{C}$ for $30 \mathrm{~s}$ (single; 45-cycle quantification), $40^{\circ} \mathrm{C}$ for $10 \mathrm{~s}$ (1-cycle). Efficiency of the PCR-reaction was confirmed with standard curve analysis. Sample quantifications were normalized to glyceraldehyde-3-phosphate dehydrogenase (GAPDH) expression. Primers were obtained from TIB Molbiol (Berlin, Germany), their sequences and UPL probes used are represented on Table 1. Evaluation was performed with the LightCycler480 SW1.5 software (Roche, Mannheim, Germany).

\section{Rat model of heart transplantation}

Experimental groups. Rats $(\mathrm{n}=72)$ were randomly divided into 3 groups for each protocol. First study: (1) $1 \mathrm{~h}$ ischemia/1 h reperfusion group ( $1 \mathrm{~h} \mathrm{I} / \mathrm{R})$; (2) ethanol-treatment $6 \mathrm{~h}$ before explantation followed by $1 \mathrm{~h}$ ischemia/ $1 \mathrm{~h}$ reperfusion $(6 \mathrm{~h}$ ethanol+1 h I/R), and (3) ethanol-treatment $24 \mathrm{~h}$ before explantation followed by $1 \mathrm{~h}$ ischemia/ $1 \mathrm{~h}$ reperfusion groups $(24 \mathrm{~h}$ ethanol+1 h I/R).

In the second study, the influence of ethanol exposure on longterm has been investigated: (1) $1 \mathrm{~h}$ ischemia/24 h reperfusion group (24 h I/R); (2) ethanol-treatment $6 \mathrm{~h}$ before explantation followed by $1 \mathrm{~h}$ ischemia/24 $\mathrm{h}$ reperfusion $(6 \mathrm{~h}$ ethanol+24 $\mathrm{h} \mathrm{I} /$
$\mathrm{R})$, and (3) ethanol-treatment $24 \mathrm{~h}$ before explantation followed by $1 \mathrm{~h}$ ischemia/24 h reperfusion groups ( $24 \mathrm{~h}$ ethanol+1 $\mathrm{h} \mathrm{I} / \mathrm{R}$ ).

Method of heart transplantation. Transplantations were performed in isogeneic Lewis to Lewis rat strain, therefore no organ rejection can be expected. The donor-rats of the ethanol groups received a single intraperitoneal injection of ethanol $(3.45 \mathrm{~g} / \mathrm{kg})$ either $6 \mathrm{~h}$ or $24 \mathrm{~h}$ prior to explantation. The donorrats of the control groups received saline instead.

The experimental model was established according to the reported method [14]. Briefly, the donor rats were anaesthetized with intraperitoneal injection of xylazine $(3 \mathrm{mg} / \mathrm{kg})$ and ketamine $(100 \mathrm{mg} / \mathrm{kg})$ and heparinized $(400 \mathrm{IU} / \mathrm{kg})$. A bilateral thoracotomy was performed to expose the heart. After cardiac arrest the superior and inferior caval veins and the pulmonary veins were tied en masse with a 4-0 single silk suture and the heart was stored in cold histidine-tryptophan-ketoglutarate solution (Custodiol, $4^{\circ} \mathrm{C}$ ). The recipient rats were anaesthetized with xylazine and ketamine and then heparinized. The aorta and the pulmonary artery of the donor heart were anastomosed end to side to the abdominal aorta and the vena cava of the recipient rat, respectively. To minimize variability between experiments, the duration of the implantation was standardized at $1 \mathrm{~h}$ (ischemic period). After the completion of the anastomoses, the heart was then reperfused with blood in situ for $1 \mathrm{~h}$ or $24 \mathrm{~h}$.

Hemodynamic measurements. One hour or $24 \mathrm{~h}$ after transplantation a $3 \mathrm{~F}$ latex balloon catheter (Edwards Lifesciences Corporation, Irvine, CA, USA) was introduced into the left ventricle via the apex for administration and withdrawal of fluid to determine $\mathrm{dP} / \mathrm{dt}_{\max }, \mathrm{dP} / \mathrm{dt}_{\min }$, developed pressure, $\mathrm{LV}$ systolic pressure and LV end-diastolic pressure by a Millar micromanometer (Millar Instruments, Houston, TX, USA) at different LV volumes. From these data LV pressure-volume relationships were constructed using PVAN3.6 software (Millar Instruments, Houston, TX, USA).

Thiobarbituric acid reactive substance (TBARS) assay. Heart TBARS concentration was measured by a commercial kit (Zeptometrix Corporation, Buffalo, New York, USA). Briefly, the homogenate was mixed with sodium dodecyl sulfate (SDS) solution and thiobarbituric acid/Buffer Reagent with thorough shaking, and heated for $60 \mathrm{~min}$ at $95^{\circ} \mathrm{C}$. The samples were then cooled to room temperature in an ice bath for $10 \mathrm{~min}$. The absorbance in the supernatant after centrifugation at $3000 \mathrm{rpm}$ for $15 \mathrm{~min}$ was measured at $532 \mathrm{~nm}$ using a spectrophotometer (Thermo Electron Corporation, Waltham, Massachusetts, USA).

\section{Western Blotting}

Myocardial proteins were extracted into a solution containing $8 \mathrm{M}$ urea, $5 \mathrm{mM}$ EDTA, $0.002 \%$ trasylol, $0.05 \mathrm{mM}$ phenylmethanesulfonylfluoride (PMSF), 0,003\% TritonX-100 containing protease inhibitors (Roche, Mannheim, Germany). Protein concentration was determined by a commercial kit according to the manufacturer's protocol (bicinchoninic acid, BCA protein assay kit; Thermo Scientific, Rockford, USA). Total protein homogenates $(30 \mu \mathrm{g})$ were denatured, separated on sodium dodecyl sulfate polyacrylamide gel electrophoresis (SDS-PAGE) gradient gels (Invitrogen, Darmstadt, Germany) and transferred to polyvinylidene fluoride (PVDF) membrane (Invitrogen, Darmstadt, Germany). The membranes were blocked with $5 \%$ milk in TrisBuffered Saline Tween 20 before incubation overnight at $4^{\circ} \mathrm{C}$ with primary antibodies specific to superoxide dismutase (SOD)-1 (1:10000, Abcam, Cambridge, UK), cytochrome-c oxidase (1:1000, New England Biolabs GmbH, Frankfurt am Main), glutathione peroxidase (GPx)-4 (1:10000, Abcam, Cambridge, 
Table 1. The sequence for the forward (F) and reverse (R) primers (from $5^{\prime}$ to $3^{\prime}$ ) and Universal Probe Library (UPL) probes.

\begin{tabular}{|c|c|c|}
\hline Assay & Sequence & UPL probes \\
\hline Cytochrome c oxidase & $\begin{array}{l}\text { F:5'- AGCCAAATCTCCCACTTCC -3' } \\
\text { R: 5'- ATAGCTCTCCAAGTGGGATAAGAC - } 3 \text { ' }\end{array}$ & 18 \\
\hline GAPDH & $\begin{array}{l}\text { F:5'- AGCTGGTCATCAATGGGAAA -3' } \\
\text { R: 5'- CGGCAGGTCCTTCTCTATCA -3' }\end{array}$ & 9 \\
\hline GPx4 & $\begin{array}{l}\text { F:5'- TGGGAAATGCCATCAAATG -3' } \\
\text { R: 5'- CGGCAGGTCCTTCTCTATCA -3' }\end{array}$ & 25 \\
\hline $\mathrm{Ca}_{\mathrm{v}} 1.2, \alpha_{1 c^{-} \text {-subunit }}$ & $\begin{array}{l}\text { F:5'- GAGGGCTGGACAGACGTG -3' } \\
\text { R:5'- TGACCCTATGATGATTAGTGTTACAAA -3' }\end{array}$ & 81 \\
\hline $\begin{array}{l}\mathrm{Na}^{+}-\mathrm{K}^{+}-\mathrm{ATPase} \\
\text { ( } \alpha_{1} \text {-subunit) }\end{array}$ & $\begin{array}{l}\text { F:5' - CACCAAGATAGTGGAGATTCCTTT -3' } \\
\text { R:5' - TGGGTTCTTGTGAATGGAGA -3' }\end{array}$ & 22 \\
\hline SERCA-2 & $\begin{array}{l}\text { F:5'- ATGGACGAGACGCTCAAGTT -3' } \\
\text { R:5'- GTTTAGGAAGCGGTTACTCCAG -3' }\end{array}$ & 1 \\
\hline SOD-1 & $\begin{array}{l}\text { F:5'- GGTCCAGCGGATGAAGAG - } 3^{\prime} \\
\text { R:5'- GGACACATTGGCCACACC - } 3^{\prime}\end{array}$ & 5 \\
\hline MMP-9 & $\begin{array}{l}\text { F:5'- GGTCAGGTTTAGAGCCACGA -3' } \\
\text { R:5'- CCTCTGCATGAAGACGACATAA - 3' }\end{array}$ & 42 \\
\hline TNF- $\alpha$ & $\begin{array}{l}\text { F:5'- GCCCAGACCCTCACACTC-3' } \\
\text { R:5'- CCACTCCAGCTGCTCCTCT-3' }\end{array}$ & 119 \\
\hline Inducible NOS & $\begin{array}{l}\text { F:5'- CAGCGGCTCCATGACTCT-3' } \\
\text { R:5'- ATCTCCTGCATTTCTTCCTGAT-3' }\end{array}$ & 82 \\
\hline
\end{tabular}

Glyceraldehyde 3-phosphate dehydrogenase (GAPDH), glutathione peroxidase (GPx)-4, L-Type calcium-channel ( $\alpha$ 1c-subunit; Ca 1.2 ), sodium-potassium Adenosine Triphosphatase ( $\mathrm{Na}^{+}-\mathrm{K}^{+}$-ATPase), sarco(endo)plasmic $\mathrm{Ca}^{2+}$-ATPas (SERCA)-2, superoxide dismutase (SOD)-1, matrix metalloproteinase (MMP)-9, tumor necrosis factor (TNF)- $\alpha$, inducible nitric oxide synthase (NOS).

doi:10.1371/journal.pone.0049237.t001

UK), metalloproteinase (MMP)-9 (1:100, Santa Cruz, Biotehnology, Heidelberg, Germany) and cardiac troponin I (1:5000, Abcam, Cambridge, UK). After washing blots to remove excessive primary antibody binding, blots were incubated for $1 \mathrm{~h}$ with horseradish peroxydase conjugated secondary antibody (1:5000, Santa Cruz Biothechnology, Heidelberg, Germany). The immunoreactive protein bands were developed using Enhanced Chemiluminescence system (PerkinElmer, Rodgau-Juegesheim, Germany). The intensity of immunoblot bands was detected with a Fujifilm LAS-3000 Imager.

\section{Chemical reagent}

Ethanol absolute, sodium chloride, Triton X-100 were bought from Sigma-Aldrich (Steinheim, Germany). Custodiol was purschased from Dr Franz Köhler Chemie GmbH (AlsbachHähnlein, Germany), sodium pentobarbital from Merial GmbH (Halbergmoos, Germany), heparin sodium from Ratiopharm $\mathrm{GmbH}$ (Ulm, Germany), buffered paraformaldehyde 4\% from Carl Roth GmbH (Karlsruhe, Germany), PBS from Genaxxon Bioscience GmbH (Ulm, Germany), Tris-Buffered Saline Tween 20 from Thermo Fisher Scientific (Cheshire, UK), BSA from Invitrogen Corporation (Auckland, New Zealand), xylene from National Diagnostics (Atlanta, USA), and EDTA from Applied Chem (Darmstadt, Germany).

\section{Statistical analysis}

All data are expressed as means \pm standard error of the mean (S.E.M). Means between groups were compared by 1-way ANOVA followed by an unpaired t test with Bonferroni correction for multiple comparisons. A value of $\mathrm{p}<0.05$ was considered statistically significant.

\section{Results}

\section{Effect of ethanol exposure on the heart}

Effect of ethanol exposure on cardiac function. Whereas ethanol exposure had no effect on heart rate, systolic and diastolic blood pressures, mean arterial pressure and LV end-systolic pressure were significantly reduced at $1 \mathrm{~h}$ and $6 \mathrm{~h}$ and recovered $24 \mathrm{~h}$ after ethanol administration compared with the control group (Table 2). Assessment of load-dependent ( $\left.\mathrm{dP} / \mathrm{dt}_{\mathrm{max}}\right)$, load independent $\left(\mathrm{dP} / \mathrm{dt}_{\max } / \mathrm{EDV}\right)$ contractility parameters, and $\mathrm{LV}$ end-diastolic pressure revealed a significant decline only at $1 \mathrm{~h}$ in response to acute ethanol when compared with the control group (Figure 1A-1B, Table 2). Whereas $1 \mathrm{~h}$ and $6 \mathrm{~h}$ after ethanol administration myocardial relaxation $\left(\mathrm{dP} / \mathrm{dt}_{\min }\right)$ was significantly decreased, EDPVR was significantly increased in rats treated with ethanol after $1 \mathrm{~h}, 6 \mathrm{~h}$ and $24 \mathrm{~h}$, indicating increased end-diastolic stiffness (Figure 1C-1D).

Effect of ethanol exposure on ECG parameters and cardiac troponin-T levels. Ethanol-treated rats showed a marked elevation in ST-segments at $24 \mathrm{~h}$ and elongated corrected QT interval at $6 \mathrm{~h}$ and $24 \mathrm{~h}$ when compared with the control group (Figure 2A-2C). Following ethanol administration, plasma cardiac troponin- $T$ levels remained elevated after $1 \mathrm{~h}, 6 \mathrm{~h}$ and $24 \mathrm{~h}$ (Table 3).

Effect of ethanol exposure on myocardial histology and DNA strand breaks. Histological examination revealed that at $24 \mathrm{~h}$ following ethanol administration, cardiomyocyte transverse cross-section area was significantly increased in the H\&E-stained sections compared with the control-group and there was no sign of myocardial inflammation (Figure 3A-3B). Using TUNEL assay, we found pronounced DNA-damage in the myocardium of rats treated with ethanol at $24 \mathrm{~h}$, as reflected by quantitative assessment of TUNEL-positive cells (containing red fluorescent nuclei), indicating DNA-fragmentation (Figure 4A-4D). 

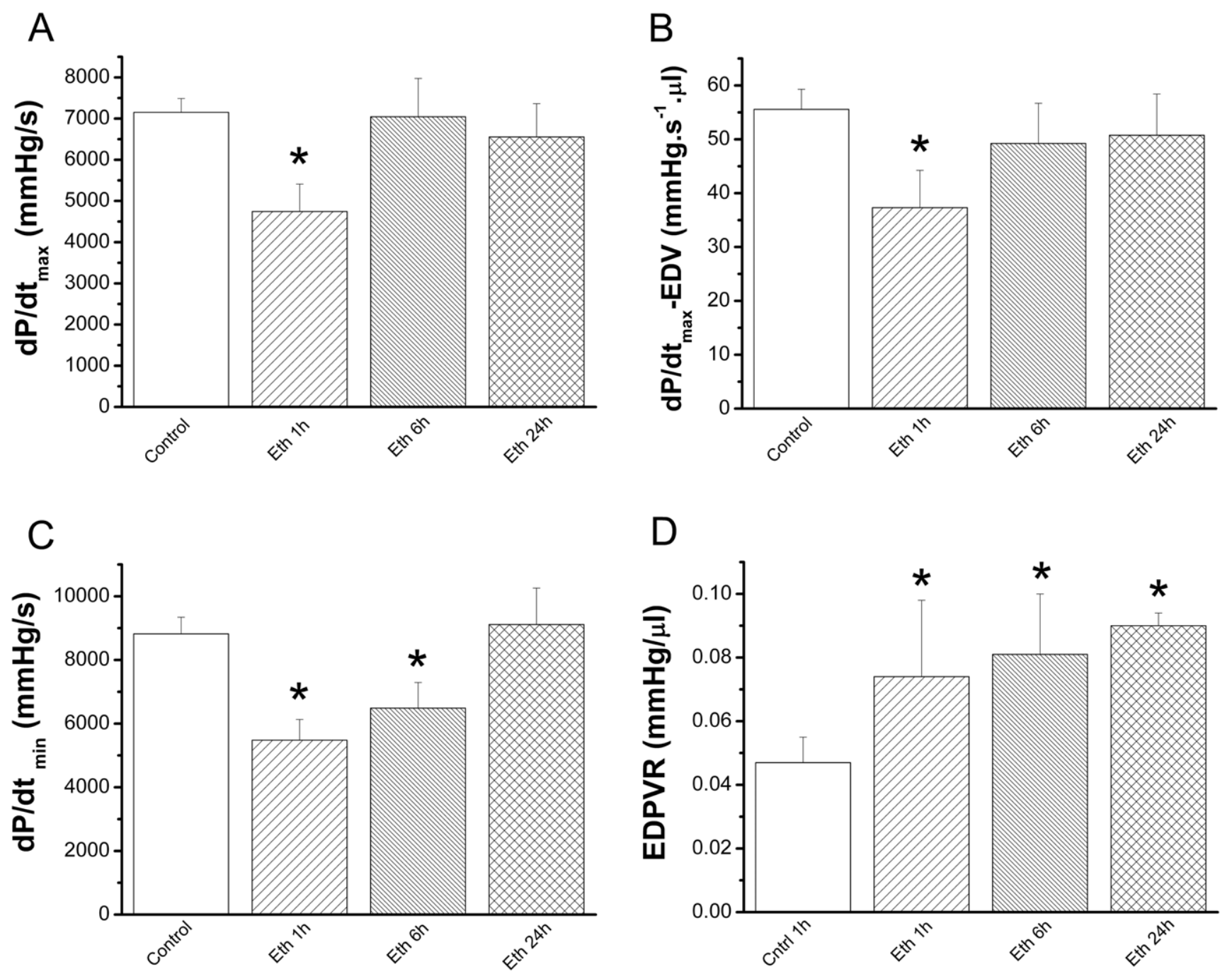

Figure 1. Effect of acute ethanol exposure on cardiac function. Assessment of $(A)$ load-dependent $\left(d P / d t_{\text {max }}\right)$ and $(B)$ load-independent $(d P /$ $\mathrm{dt}_{\text {max }}-\mathrm{EDV}$ ) contractility parameters revealed a significant decline only at $1 \mathrm{~h}$ in response to acute ethanol when compared with the control group. Whereas (C) maximal slope of the diastolic pressure decrement $\left(\mathrm{dP} / \mathrm{dt}_{\min }\right) 1 \mathrm{~h}$ and $6 \mathrm{~h}$ after ethanol administration was significantly decreased, (D) end-diastolic pressure-volume relationship (EDPVR) was significantly increased in rats treated with ethanol after $1 \mathrm{~h}, 6 \mathrm{~h}$ and $24 \mathrm{~h}$. Eth indicates ethanol. ${ }^{*} \mathrm{p}<0.05$ versus control.

doi:10.1371/journal.pone.0049237.g001

Table 2. Cardiac hemodynamic parameters.

\begin{tabular}{|c|c|c|c|c|}
\hline Parameters & Control & Ethanol $1 \mathrm{~h}$ & Ethanol $6 \mathrm{~h}$ & Ethanol $24 \mathrm{~h}$ \\
\hline Heart rate, beats $/ \mathrm{min}$ & $345 \pm 16$ & $353 \pm 23$ & $399 \pm 38$ & $390 \pm 28$ \\
\hline SBP, mmHg & $112 \pm 4$ & $80 \pm 5^{*}$ & $80 \pm 7^{*}$ & $104 \pm 7$ \\
\hline $\mathrm{DBP}, \mathrm{mmHg}$ & $83 \pm 5$ & $51 \pm 4^{*}$ & $42 \pm 5^{*}$ & $77 \pm 7$ \\
\hline MAP, mmHg & $93 \pm 4$ & $61 \pm 5^{*}$ & $59 \pm 5^{*}$ & $86 \pm 7$ \\
\hline LVESP, mmHg & $100 \pm 5$ & $73 \pm 7^{*}$ & $66 \pm 3^{*}$ & $86 \pm 7$ \\
\hline LVEDP, mmHg & $7.6 \pm 0.5$ & $5.7 \pm 0.5^{*}$ & $6.5 \pm 1.1$ & $7.9 \pm 1.1$ \\
\hline
\end{tabular}

SBP: systolic blood pressure; DBP: diastolic blood pressure; MAP: mean arterial pressure; LVESP: left-ventricular end-systolic pressure; LVEDP: left-ventricular end-diastolic pressure.

${ }^{*} p<0.05$ versus control;

${ }^{\#} \mathrm{p}<0.05$ versus ethanol $1 \mathrm{~h}$.

doi:10.1371/journal.pone.0049237.t002
Effect of ethanol exposure on plasma glucose levels. After ethanol injection, plasma glucose levels began to increase after $1 \mathrm{~h}$ and returned towards baseline values after $6 \mathrm{~h}$ and $24 \mathrm{~h}$ (Table 3).

Effect of ethanol exposure on relative gene expression. Administration of ethanol significantly increased SOD-1, GPx-4 and cytochrome-c oxidase relative mRNA expression after $24 \mathrm{~h}$ (Figure 5A-5C) and MMP-9 mRNA-levels following $6 \mathrm{~h}$ and $24 \mathrm{~h}$ compared with the control-group (Figure 5D). Ethanol administrated rats showed a significant down regulation of TNF- $\alpha$ mRNA expression at $1 \mathrm{~h}(0.31 \pm 0.07$ versus $0.71 \pm 0.16, \mathrm{p}<0.05)$ and inducible NOS mRNA-levels at $1 \mathrm{~h}(0.60 \pm 0.17$ versus $1.14 \pm 0.19, \mathrm{p}<0.05)$ and $24 \mathrm{~h}(0.33 \pm 0.06$ versus $1.14 \pm 0.19, \mathrm{p}<0.05)$ when compared with the control animals. However, mRNA-levels of voltage-gated L-type calcium channel, SERCA-2 and $\mathrm{Na}^{+} / \mathrm{K}^{+}$-ATPase remained unchanged (Figure 5E-5G).

Effect of ethanol exposure on protein expression. Densitometric analysis of bands for SOD-1 showed 

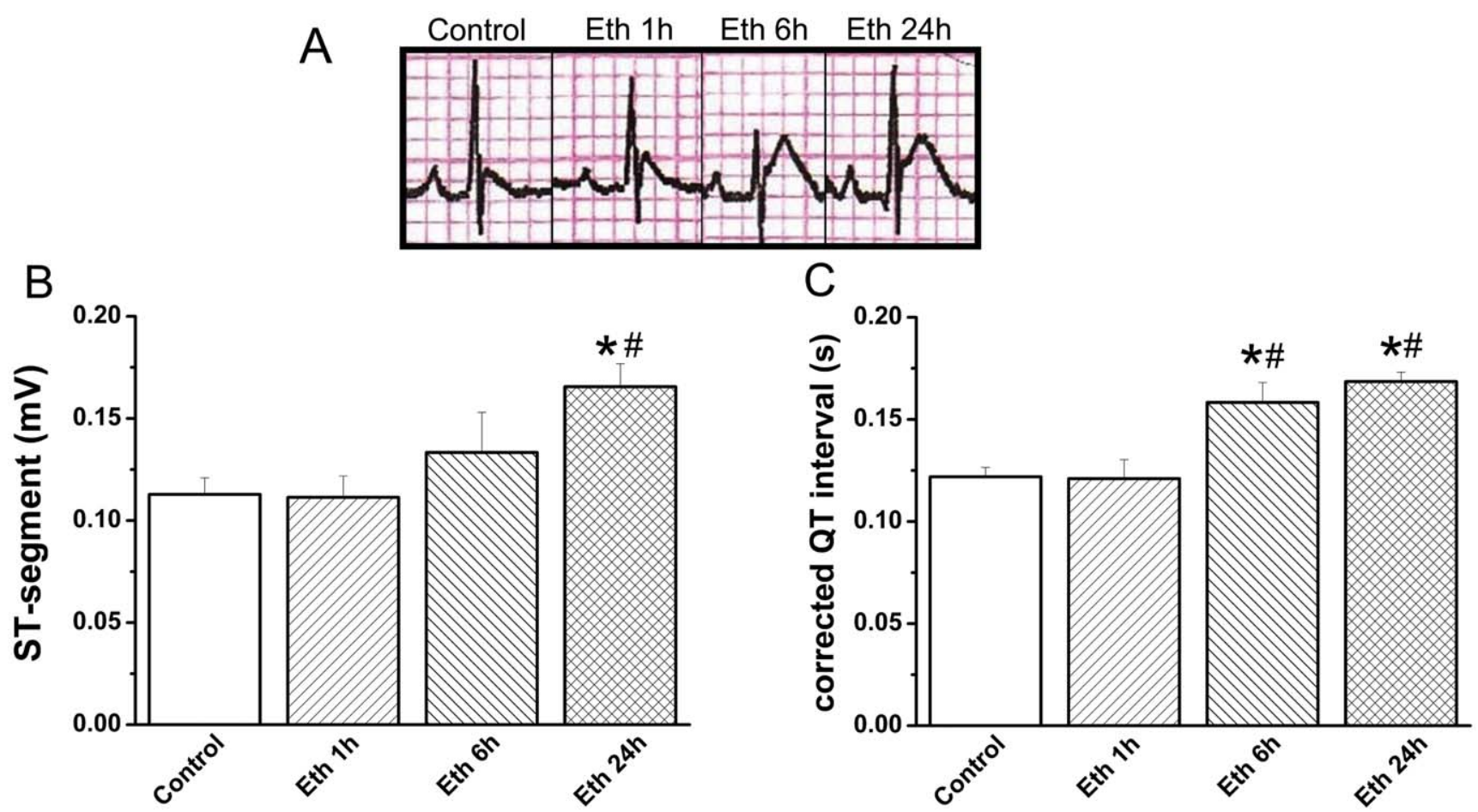

Figure 2. Effect of acute ethanol exposure on electrocardiographic patterns. (A) Representative electrocardiogram tracings. Rats treated with ethanol showed a marked (B) ST-segment elevation at $24 \mathrm{~h}$ and (C) elongated corrected QT interval at $6 \mathrm{~h}$ and $24 \mathrm{~h}$ when compared with the control group. Eth indicates ethanol. ${ }^{*} p<0.05$ versus control; ${ }^{\#} p<0.05$ versus ethanol $1 \mathrm{~h}$.

doi:10.1371/journal.pone.0049237.g002

a significant increase at $6 \mathrm{~h}$ and $24 \mathrm{~h}$ following ethanol administration, and at $24 \mathrm{~h}$ for GPx4 (Figure 6A-6B), cytochrome-c oxidase and MMP-9 (Figure 6C-6D), compared with the control group. However, protein levels of voltage-gated L-type calcium channel, SERCA-2 and $\mathrm{Na}^{+} / \mathrm{K}^{+}$-ATPase remained unchanged (data not shown).

\section{Effect of ethanol exposure on the transplanted heart}

Effect of ethanol exposure on donor heart function after transplantation. One hour and $24 \mathrm{~h}$ after transplantation, in which donors received ethanol $6 \mathrm{~h}$ or $24 \mathrm{~h}$ prior to explantation, significantly lower $\mathrm{dP} / \mathrm{dt}_{\max }$ and $\mathrm{dP} / \mathrm{dt}_{\text {min }}$ were observed when compared with the control-group, indicating decrease myocardial contractility and relaxation (Figure 7A-7B; Figure 7E-7F). Although LV systolic pressure and LV developed pressure, as indexes of myocardial contractile function, were significantly decreased in the $24 \mathrm{~h}$ ethanol+1 h I/R group (Figure 7C-7D), $\mathrm{LV}$ end-diastolic pressure, as a marker of the standardised ballooncatheter measurements did not show any major differences (data not shown) $1 \mathrm{~h}$ after transplantation. However, $24 \mathrm{~h}$ after transplantation, LV systolic pressure and LV developed pressure were significantly decreased in both $6 \mathrm{~h}$ ethanol+24 h I/R and $24 \mathrm{~h}$ ethanol+24 h I/R groups compared with the control-group (Figure 7G-7H). Ethanol administration had no effect on heart rate $1 \mathrm{~h}$ after transplantation $(225 \pm 11$ beats/min $1 \mathrm{~h} \mathrm{I} / \mathrm{R}$ group versus $230 \pm 14$ beats/min $6 \mathrm{~h}$ ethanol+1 h I/R group versus $254 \pm 25$ beats/min $24 \mathrm{~h}$ ethanol+1 h I/R group) and $24 \mathrm{~h}$ after transplantation $(207 \pm 13$ beats $/ \mathrm{min} 24 \mathrm{~h} \mathrm{I} / \mathrm{R}$ group versus $230 \pm 15$ beats/min $6 \mathrm{~h}$ ethanol+24 h I/R group versus $211 \pm 34$ beats/min $24 \mathrm{~h}$ ethanol+24 h I/R group).

Effect of ethanol exposure on graft TBARS concentration after heart transplantation. One hour and $24 \mathrm{~h}$ after transplantation, there was a significant increase in graft TBARS concentration in the group receiving ethanol $24 \mathrm{~h}$ prior to explantation when compared with the control- and $6 \mathrm{~h}$ ethanol+I/R groups (Figure 8A-8B).

Effect of ethanol exposure on graft protein expression after heart transplantation. Twenty-four hours after transplantation, densitometric analysis of bands for SOD-1 showed a significant increase at $6 \mathrm{~h}$ and $24 \mathrm{~h}$ following ethanol administra-

Table 3. Time-course of changes in plasma cardiac troponin-T and glucose levels after acute ethanol administration.

\begin{tabular}{|c|c|c|c|c|}
\hline & Control & Ethanol $1 \mathrm{~h}$ & Ethanol $6 \mathrm{~h}$ & Ethanol $24 \mathrm{~h}$ \\
\hline Cardiac troponin-T, pg/ml & $76 \pm 11$ & $201 \pm 82^{*}$ & $224 \pm 73 *$ & $200 \pm 60^{*}$ \\
\hline Glucose, mg/dl & $174 \pm 5$ & $343 \pm 113 *$ & $227 \pm 98$ & $182 \pm 20$ \\
\hline
\end{tabular}



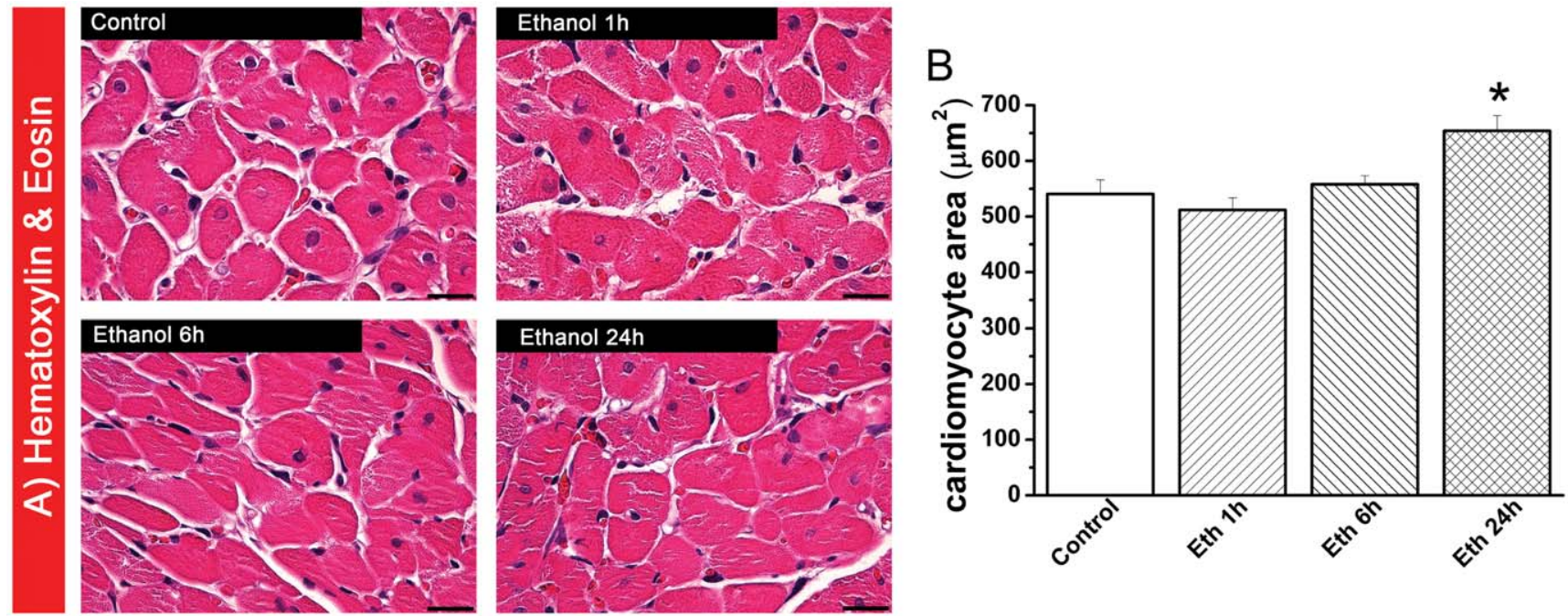

Figure 3. Histological analysis following acute ethanol exposure. (A) Hematoxylin and eosin (H\&E) staining micrographs of transverse sections of myocardium (magnification $\times 400$; scale bar: $20 \mu \mathrm{m}$ ) and (B) quantitative analysis of cardiomyocyte cross-sectional area using measurements of $\sim 20$ cardiomyocytes in each group. Twenty-four hours after ethanol administration, the cardiomyocyte transverse cross-section area was significantly increased in the H\&E staining sections compared with the control group. Eth indicates ethanol. * $<0.05$ versus control. doi:10.1371/journal.pone.0049237.g003

tion, at $6 \mathrm{~h}$ for cytochrome-c oxidase, and at $24 \mathrm{~h}$ for MMP-9 compared with the control group (Figure 9A, 9C, 9D). Moreover, $24 \mathrm{~h}$ after transplantation, there was a significant increase in protein expression for GPx4 in the group receiving ethanol $24 \mathrm{~h}$ prior to explantation when compared with the control- and 6 h ethanol+24 I/R groups (Figure 9B).

Effect of ethanol exposure on graft Troponin I expression after heart transplantation. One hour and $24 \mathrm{~h}$ after transplantation, graft Troponin I expression was significantly increased in the groups receiving ethanol $6 \mathrm{~h}$ or $24 \mathrm{~h}$ prior to explantation when compared with the respective control groups (Figure 10A-10B).

\section{Discussion}

The major finding of this present study is that acute alcohol abuse increases the susceptibility of donor hearts to ischemia/ reperfusion injury in a rat model of heart transplantation even though global heart contractile function recovers $6 \mathrm{~h}$ after ethanol administration.
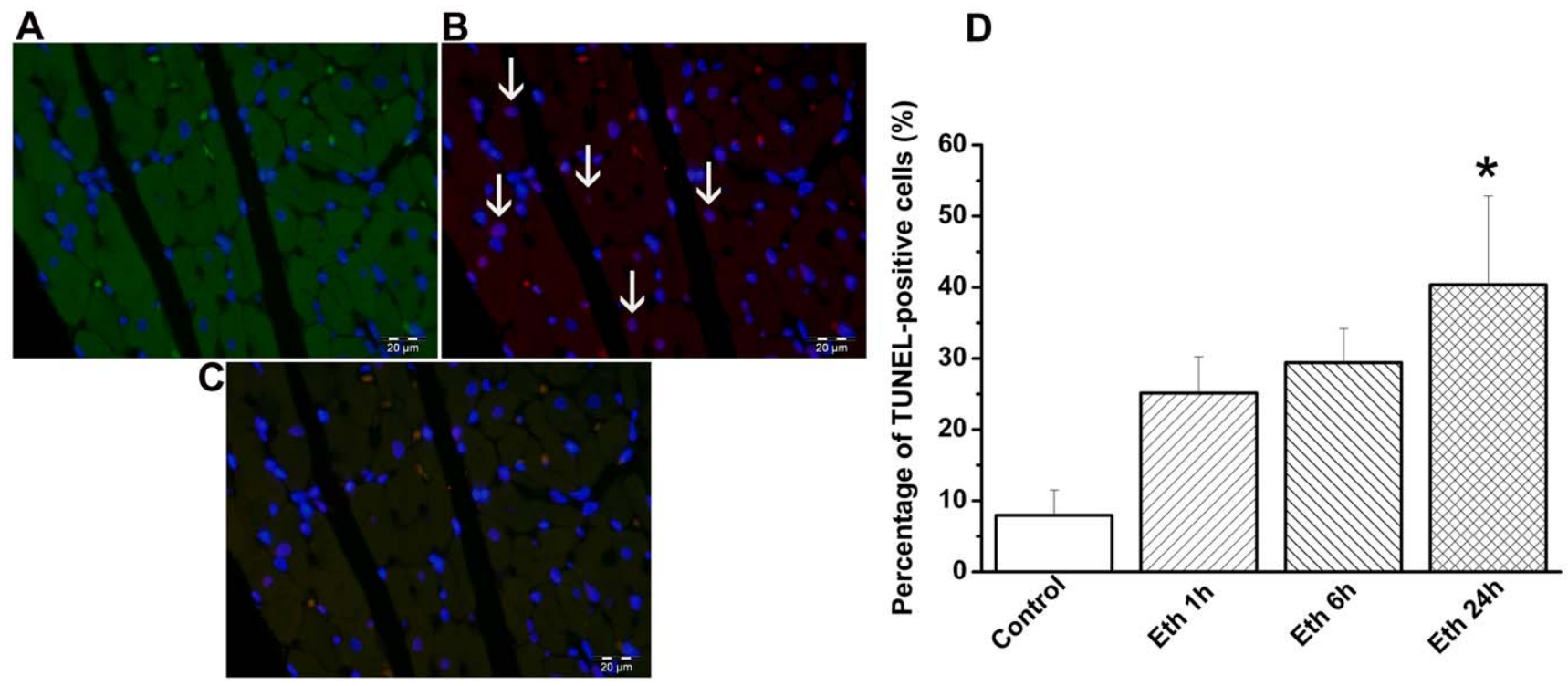

Figure 4. Effect of acute ethanol exposure on DNA-strand breaks in cardiomyocytes. Representative photomicrographs of (A) cardiomyocytes stained with cardiac troponin I (green) and nuclei with 4', 6-diamidino-2-phenylindole (DAPI, blue), (B) nuclei with fragmented DNA visualized by TUNEL staining (red), and (C) merged image. Magnification $\times 400$; scale bar: $20 \mu \mathrm{m}$. White arrows indicate TUNEL-positive cells (not all are marked) (D) Quantification of TUNEL-positive cells. We found DNA damage in the myocardium of rats treated with ethanol at $24 \mathrm{~h}$. Eth indicates ethanol. ${ }^{*} \mathrm{p}<0.05$ versus control.

doi:10.1371/journal.pone.0049237.g004 

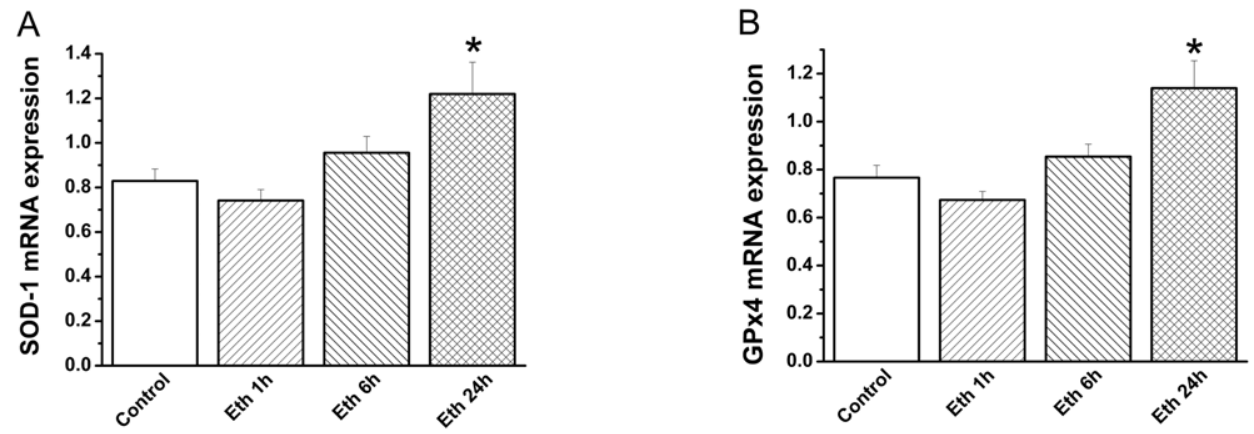

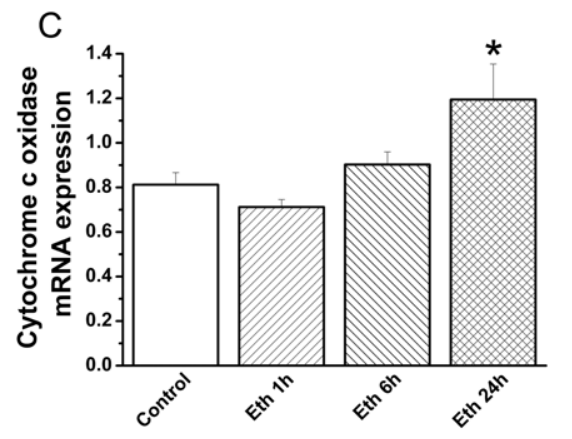

$\mathrm{F}$
D

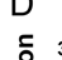

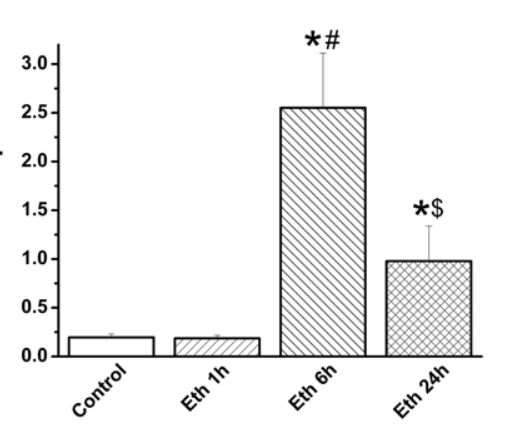
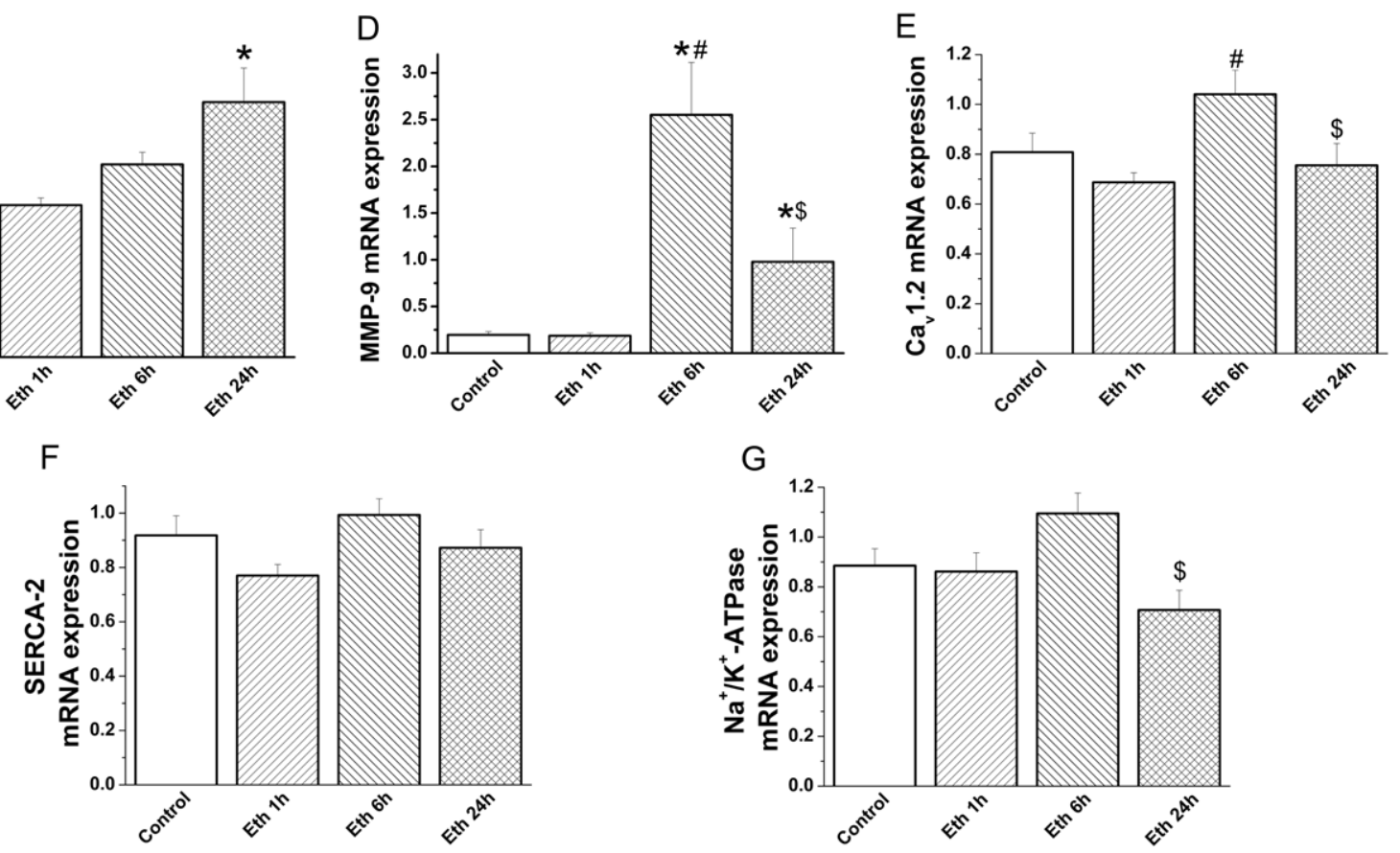

Figure 5. Effect of acute ethanol exposure on myocardial gene expression. Quantitative real-time PCR from myocardium RNA extracts revealed that mRNA levels for (A) superoxide dismutase (SOD)-1, (B) glutathione peroxydase (GPx)-4, (C) cytochrome-c oxidase were significantly increased after $24 \mathrm{~h}$ and (D) matrix metalloproteinase (MMP)-9 following $6 \mathrm{~h}$ and $24 \mathrm{~h}$ compared with the control group. However, mRNA-levels of (E) L-Type calcium-channel $\left(\mathrm{Ca}_{\mathrm{v}} 1.2\right)$, (F) sarco(endo)plasmic $\mathrm{Ca}^{2+}$-ATPase (SERCA)-2 and (G) sodium-potassium Adenosine Triphosphatase (Na $/ \mathrm{K}^{+}-$ ATPase) remained unchanged following ethanol administration compared to the control group. Eth indicates ethanol. ${ }^{*} p<0.05$ versus control, $\# p<0.05$ versus ethanol $1 \mathrm{~h},{ }^{5} \mathrm{p}<0.05$ versus ethanol $6 \mathrm{~h}$.

doi:10.1371/journal.pone.0049237.g005

In the present study, we focussed our attention on acute ethanol exposure in which the total consumption is compressed into a short period of time to mimic binge drinking. A bolus of ethanol at a standard dose of $3.45 \mathrm{~g} / \mathrm{kg}$ body weight, intraperitoneally ensures a complete bioavailability and succeeded in producing rapid rises in circulating level of ethanol. The resulting plasma ethanol concentrations were approximately 375, 185 and $0 \mathrm{mg} /$ $100 \mathrm{ml}$ at $1 \mathrm{~h}, 6 \mathrm{~h}$ and $24 \mathrm{~h}$ respectively and were similar to pathological levels occurring clinically $[15,16]$. It has been shown that ethanol damage to heart becomes evident if alcohol consumption exceeds 90 to $100 \mathrm{~g} /$ day in humans [3], which can be transpired to a dosage of $\sim 1.5 \mathrm{~g} / \mathrm{kg}$ for an adult weighing $70 \mathrm{~kg}$. In the present study we therefore used the single dose of $3.45 \mathrm{~g} / \mathrm{kg}$ of ethanol which corresponds to a state of excessive ethanol consumption, given that rodents are less sensitive than human to intoxicating effects of ethanol.

The principal indicator of myopathic alteration following ethanol exposure is characterized by compromised myocardial contractility [3]. This is supported by our results which revealed that after $1 \mathrm{~h}$, ethanol elicited deterioration in the heart function, as evidenced by reduced mean arterial pressure, load-dependent $\left(\mathrm{dP} / \mathrm{dt}_{\max }\right)$, and load-independent $\left(\mathrm{dP} / \mathrm{dt}_{\max }-\mathrm{EDV}\right)$ contractility indexes. Moreover, we observed decreased LV end-diastolic pressure at $1 \mathrm{~h}$ which recovered $6 \mathrm{~h}$ and $24 \mathrm{~h}$ after ethanol administration. This can be due to the peripheral vasodilatation and relative hypovolemia induced by ethanol, which decreases mean arterial pressure, presumably reduces the LV afterload, and subsequently preload with the consequence that the central venous pressure is lowered. It is conceivable that the systolic function was recovered at $6 \mathrm{~h}$ and $24 \mathrm{~h}$ when the ethanol levels were either low or absent but not at $1 \mathrm{~h}$. However, the continuation of ethanol's deleterious effects in the absence of circulating plasma levels, suggests that interacting phenomena are occurring. Our data demonstrated that $6 \mathrm{~h}$ and $24 \mathrm{~h}$ after alcohol administration, myocardial contractility (shown by decreased $\mathrm{dP} / \mathrm{dt}_{\max }$ ) and relaxation (evidenced by reduced $\mathrm{dP} / \mathrm{dt}_{\min }$ ) were impaired in the recipients, i.e., these rats show increased susceptibility to myocardial ischemia/reperfusion injury after heart transplanta- 


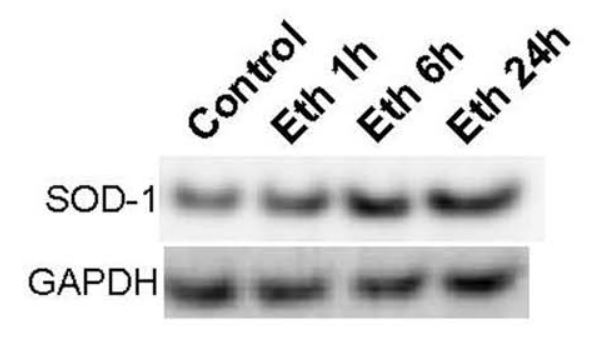

A
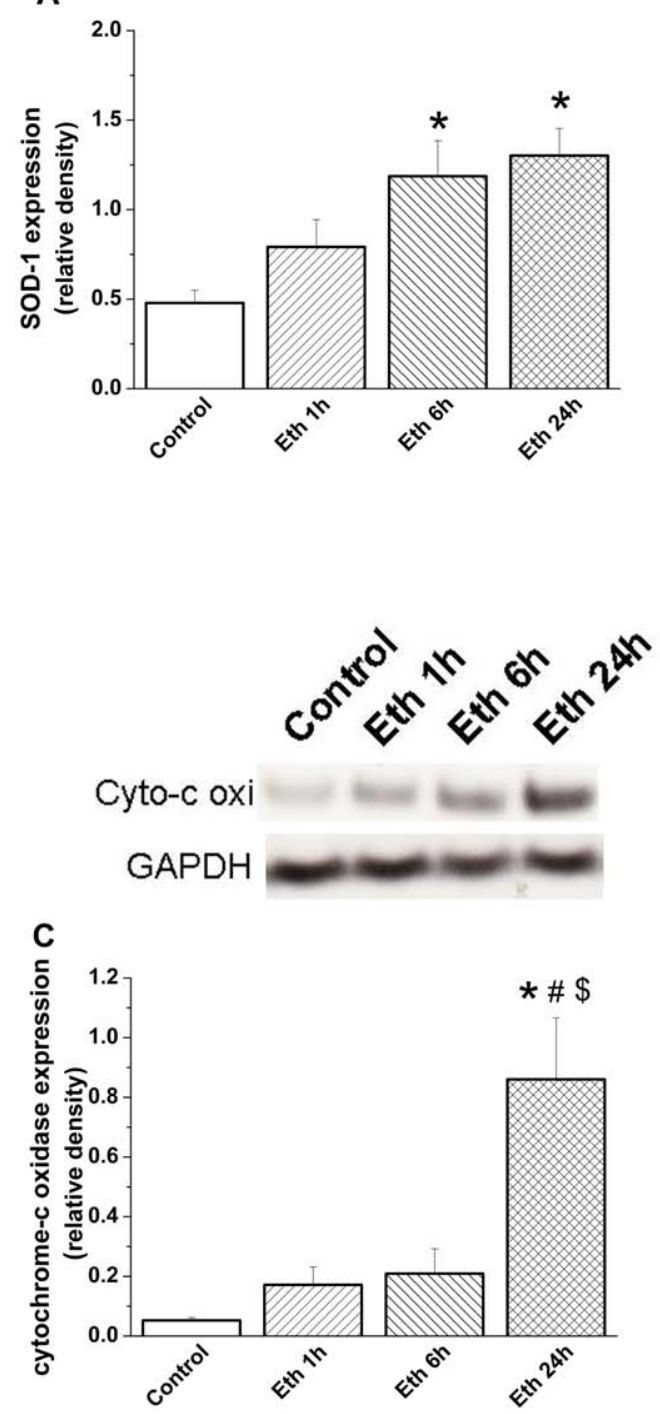
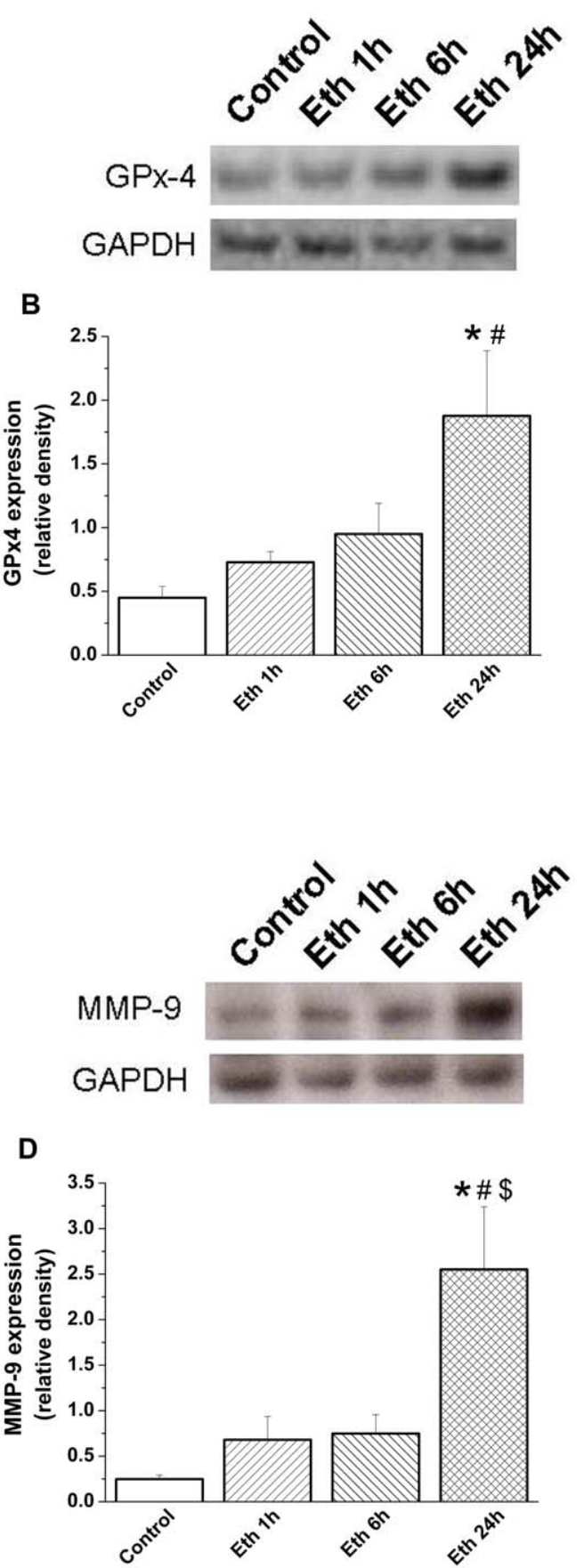

Figure 6. Effect of acute ethanol exposure on myocardial protein expression. Densitometric analysis of bands for (A) superoxide dismutase (SOD)-1 showed a significant increase after $6 \mathrm{~h}$ and $24 \mathrm{~h}$ ethanol administration, and (B) glutathione peroxidase (GPx)-4, (C) cytochrome-c oxidase (cyto-c oxi) and (D) MMP-9 following $24 \mathrm{~h}$, compared with the control group. Glyceraldehyde-3-phosphate dehydrogenase (GAPDH). Eth indicates ethanol. ${ }^{*} p<0.05$ versus control; ${ }^{\#} p<0.05$ versus ethanol $1 \mathrm{~h},{ }^{\$} \mathrm{p}<0.05$ versus ethanol $6 \mathrm{~h}$.

doi:10.1371/journal.pone.0049237.g006

tion. Although results of animal experimental studies should not be directly extrapolated to human biology, these novel results have an important implication in cardiac transplantation: acute alcohol intoxication could significantly affect myocardial sensitivity to ischemia/reperfusion even if the donor heart seems to have normal contractile function. In a mouse model of coronary artery occlusion and reperfusion, aldehydes may increase the myocardial susceptibility to ischemia/reperfusion injury [17] and moreover another model of myocardial infarction has shown that with aldehyde dehydrogenase-2 knockout condition, which is accompanied by elevated cardiac acetaldehyde levels, regional ischemia/ reperfusion injury was accentuated [18]. The EDPVR reflects the passive properties of the $\mathrm{LV}$ and used to obtain a measure of diastolic stiffness. Impaired myocardial relaxation in this study is shown by increased EDPVR for up to $24 \mathrm{~h}$ after ethanol, indicating that alcohol administration in rats also induces abnormal diastolic function. Moreover, alterations of active phase of relaxation index (as reflected by decreased $\mathrm{dP} / \mathrm{dt}_{\text {min }}$ ) were found 
A

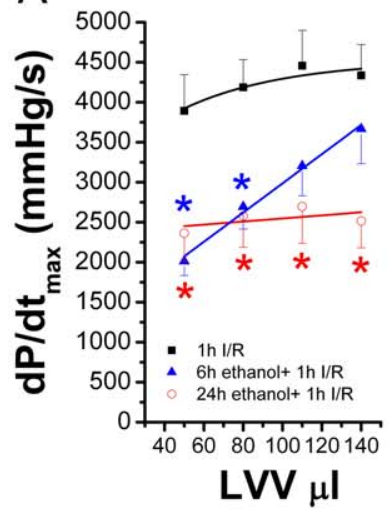

E

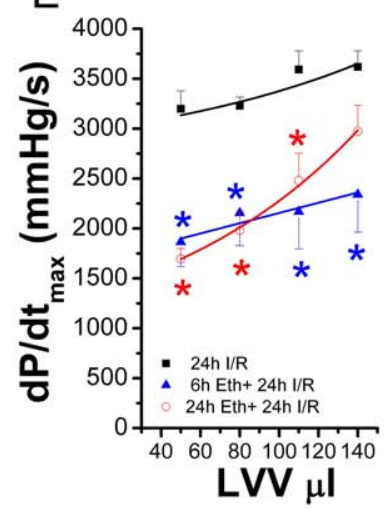

1 hour after heart transplantation

$\mathrm{B}$

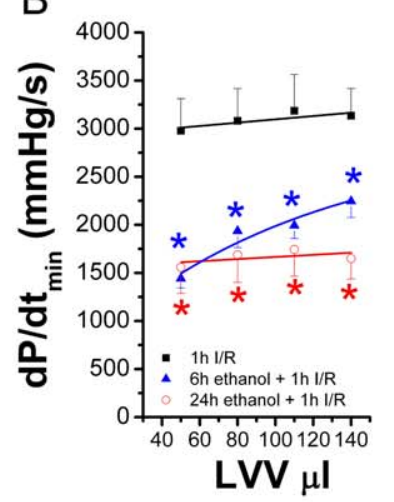

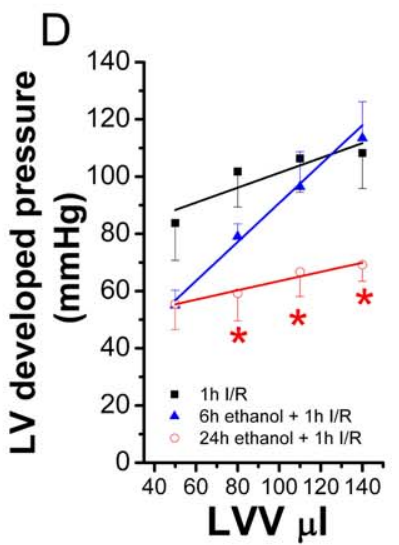

$\mathrm{H}$

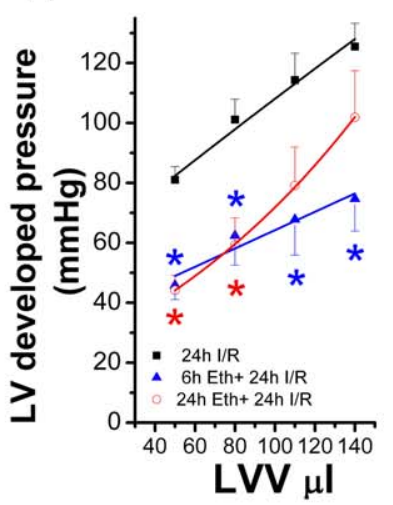

Figure 7. Effect of acute ethanol exposure on donor heart function $\mathbf{1} \mathbf{~ h}$ or $\mathbf{2 4} \mathbf{~ h}$ after transplantation. One hour and $24 \mathrm{~h}$ after transplantation, in which donors received ethanol $6 \mathrm{~h}$ or $24 \mathrm{~h}$ prior to explantation, significantly lower $(\mathrm{A}, \mathrm{E}) \mathrm{dP} / \mathrm{dt}_{\text {max }}$ (maximal slope of the systolic pressure increment) and $(B, F) d P / d t_{\text {min }}$ (maximal slope of the diastolic pressure decrement) were observed when compared with the control-group. Although (C) LV systolic pressure (LVSP) and (D) LV developed pressure, as indexes of myocardial contractile function, were significantly decreased in the $24 \mathrm{~h}$ ethanol $+1 \mathrm{~h} \mathrm{I} / \mathrm{R}$ group $1 \mathrm{~h}$ after transplantation. However, $24 \mathrm{~h}$ after transplantation, (G) LVSP and (H) LV developed pressure were significantly decreased in both $6 \mathrm{~h}$ ethanol $+24 \mathrm{~h} \mathrm{I} / \mathrm{R}$ and $24 \mathrm{~h}$ ethanol $+24 \mathrm{~h} \mathrm{I/R}$ groups compared with the control-group. I/R indicates ischemia/ reperfusion, LVV left-ventricular volume. ${ }^{*} \mathrm{p}<0.05$ versus $1 \mathrm{~h} \mathrm{I} / \mathrm{R}$ group.

doi:10.1371/journal.pone.0049237.g007
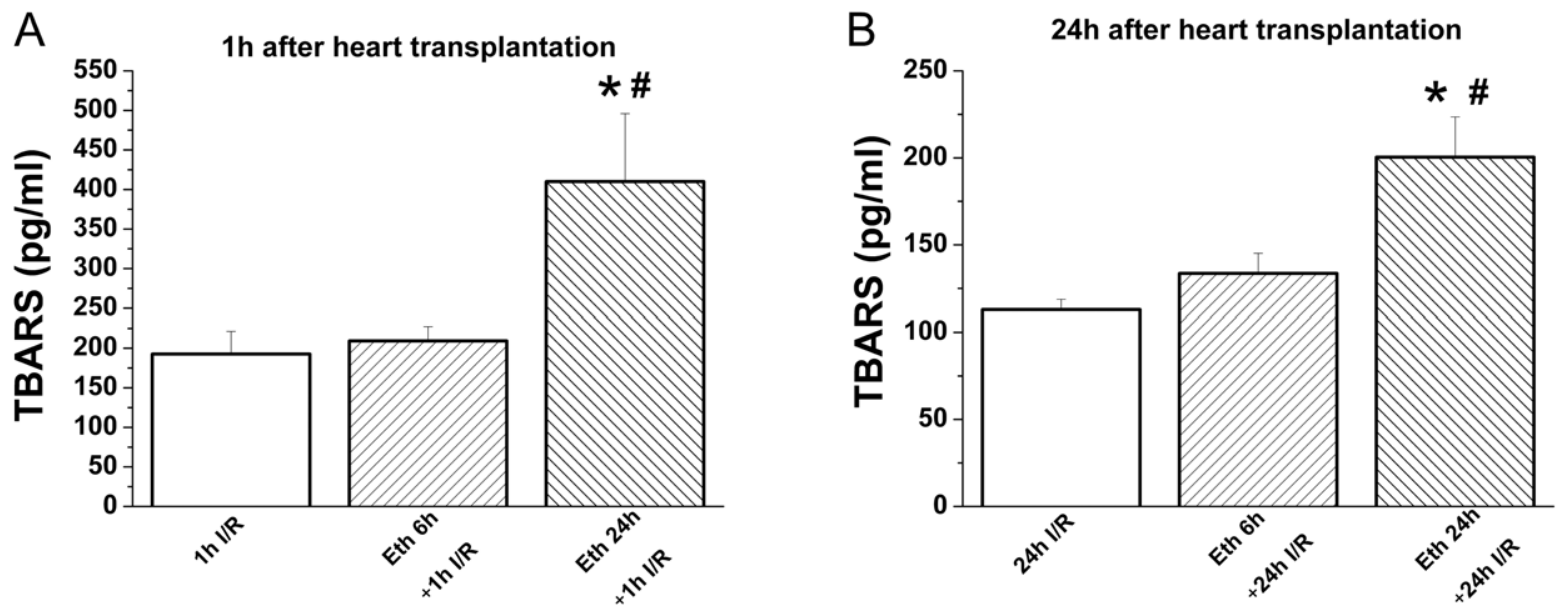

Figure 8. Effect of ethanol exposure on graft thiobarbituric acid reactive substance (TBARS) concentration $1 \mathrm{~h}$ and $24 \mathrm{~h}$ after heart transplantation. One hour and $24 \mathrm{~h}$ after transplantation, there was a significant increase in graft TBARS concentration in the group receiving ethanol $24 \mathrm{~h}$ prior to explantation when compared with the control- and $6 \mathrm{~h}$ ethanol+24 I/R groups. I/R indicates ischemia/reperfusion, Eth ethanol. ${ }^{*} p<0.05$ versus $\mathrm{I} / \mathrm{R}$ groups; ${ }^{\#} \mathrm{p}<0.05$ versus $6 \mathrm{~h}$ eth $+\mathrm{l} / \mathrm{R}$ groups. doi:10.1371/journal.pone.0049237.g008 

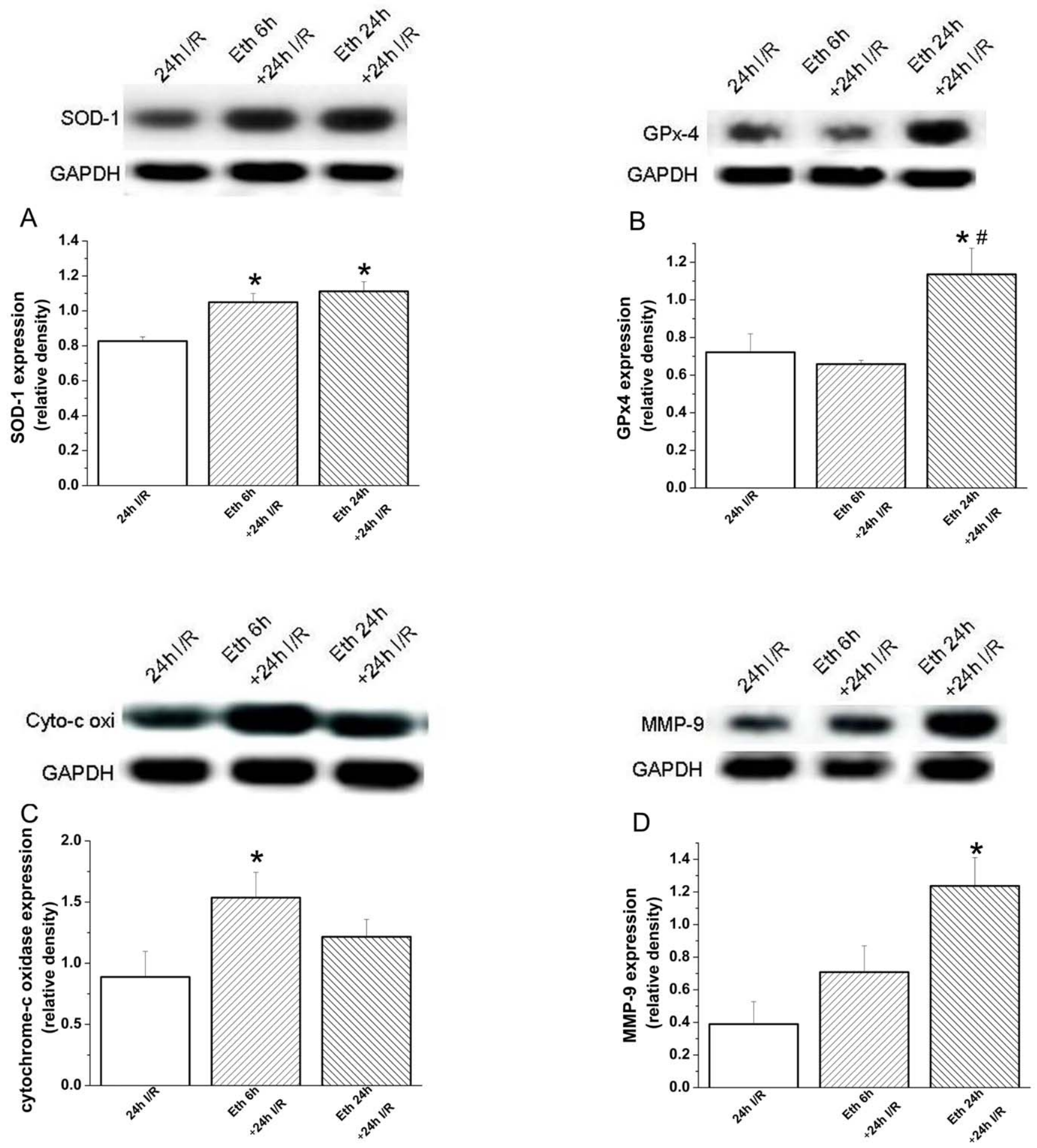

Figure 9. Effect of acute ethanol exposure on myocardial protein expression $\mathbf{2 4} \mathbf{h}$ after transplantation. Twenty-four hours after transplantation, densitometric analysis of bands for (A) superoxide dismutase (SOD)-1 showed a significant increase at $6 \mathrm{~h}$ and $24 \mathrm{~h}$ following ethanol administration, at $6 \mathrm{~h}$ for (C) cytochrome-c oxidase (cyto-c oxi), and at $24 \mathrm{~h}$ for (D) matrix metalloproteinase (MMP)-9 compared with the control group. Moreover, $24 \mathrm{~h}$ after transplantation, there was a significant increase in protein expression for (B) glutathione peroxydase (GPX)-4 in the group receiving ethanol $24 \mathrm{~h}$ prior to explantation when compared with the control- and $6 \mathrm{~h}$ ethanol+24 I/R groups. I/R indicates ischemia/reperfusion, Eth ethanol, glyceraldehyde-3-phosphate dehydrogenase (GAPDH). ${ }^{*} p<0.05$ versus $24 \mathrm{~h} \mathrm{l} / \mathrm{R}$ group; $\# \mathrm{p}<0.05$ versus $6 \mathrm{~h}$ Eth $+24 \mathrm{~h} \mathrm{I} / \mathrm{R}$ group. doi:10.1371/journal.pone.0049237.g009

to recover slowly at $24 \mathrm{~h}$ after ethanol administration, when there is no measurable blood alcohol. Taken together, these results suggest that contrary to systolic dysfunction, which was recovered
$6 \mathrm{~h}$ following ethanol, active relaxation and passive stiffness are slowly improved or sustained during $24 \mathrm{~h}$. We can speculate that the diastolic dysfunction might be at least partially due to the 

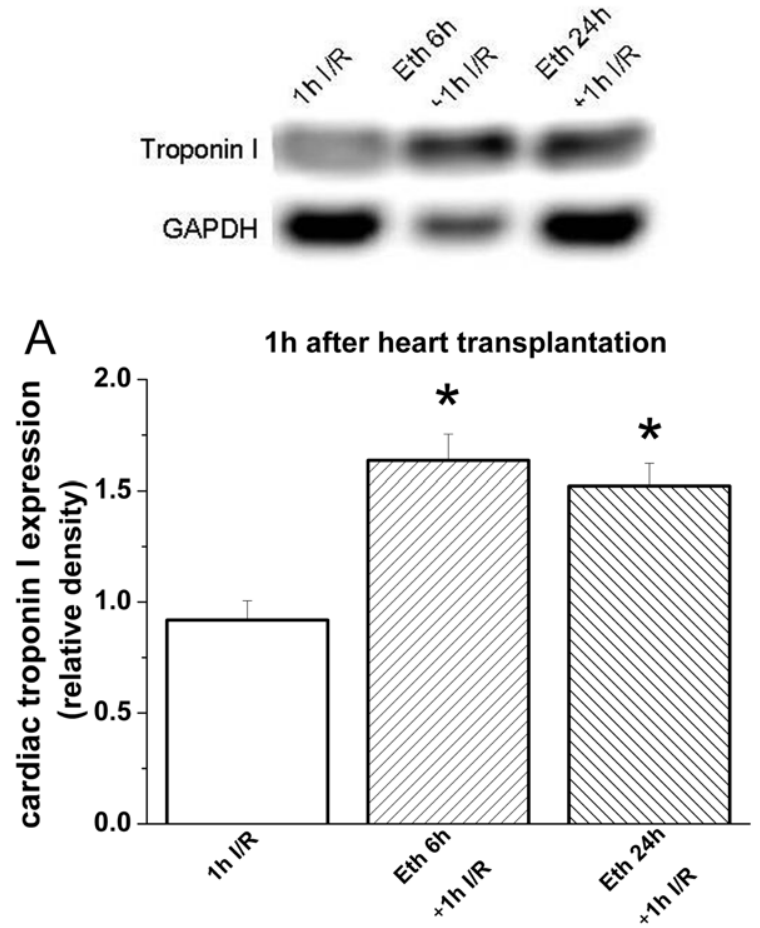
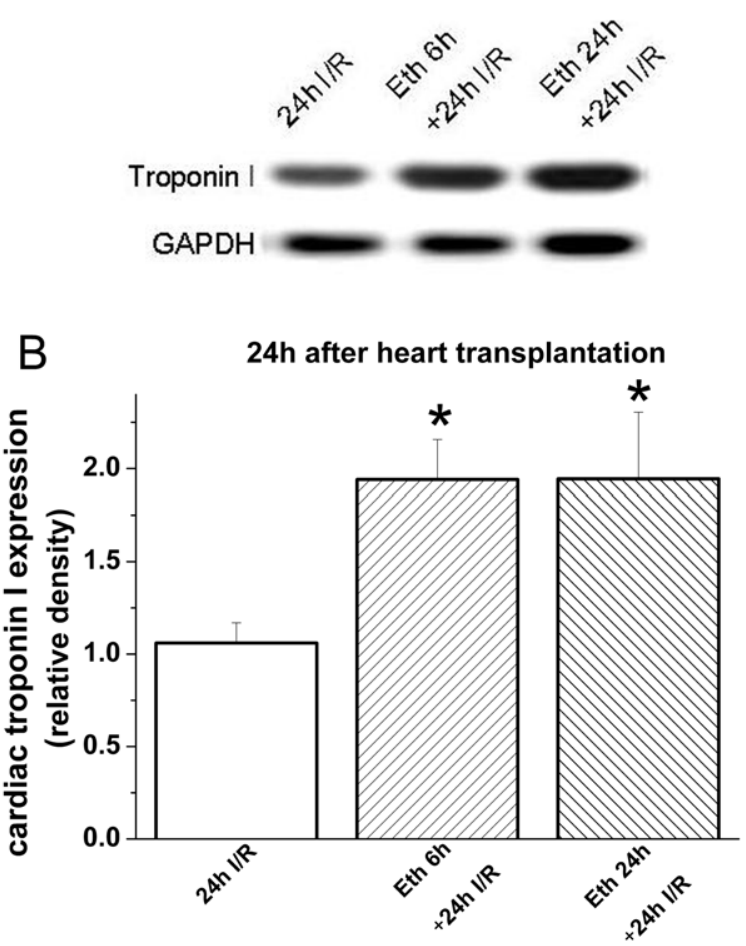

Figure 10. Effect of ethanol exposure on graft Troponin I expression $\mathbf{1} \mathbf{h}$ and $24 \mathbf{~ h}$ after heart transplantation. (A) $1 \mathrm{~h}$ and (B) $24 \mathrm{~h}$ after transplantation, graft Troponin I expression was significantly increased in the groups receiving ethanol $6 \mathrm{~h}$ or $24 \mathrm{~h}$ prior to explantation when compared with the control group. I/R indicates ischemia/reperfusion, Eth ethanol ${ }^{*} p<0.05$ versus I/R groups.

doi:10.1371/journal.pone.0049237.g010

cellular swelling. Due to the direct proportionality of the surface area and myocyte volume, the increase in myocyte profile surface area as evidence in the present work with an enlarged cardiomyocytes size $24 \mathrm{~h}$ following ethanol exposure indicates cellular swelling [19].

The donor's cardiac function has been shown to be an important prognostic factoring the clinical outcome of heart transplantation. In the present study we showed elevated circulating plasma cardiac troponin-T levels, the sensitive marker of myocardial injury in heart donors after alcohol intoxication even when hemodynamic measurement showed no evidence of impaired contractile function. A clinical study showed cardiac troponin- $\mathrm{T}>0.1 \mu \mathrm{g} / \mathrm{l}$ in the serum of heart donors to be predictive of early impaired graft function after transplantation [20]. Previously with the same bolus of ethanol on rat significant elevation in cardiac troponin-T concentration was shown at $2.5 \mathrm{~h}$ and $6 \mathrm{~h}$, but at $24 \mathrm{~h}$, in contrast to our results, the levels were not significantly different from controls [21]. It is possible that acute myocardial damage will arise as a consequence of ischemia and occurrence of cardiac arrhythmias. It has been argued that high blood acetaldehyde level might be responsible for the development of myocardial ischemia [4]. In the present study, $24 \mathrm{~h}$ after ethanol administration, ischemic damage was assessed histologically by measuring cardiomyocytes swelling and in ECG by ischemic repolarization changes by ST-segment elevation. Alcohol in modest and higher doses has the potential to induce cardiac arrhythmias. The link between alcohol intake and acute disturbances of cardiac electrophysiology has been long suggested. Administration of alcohol in humans even in moderate doses was reported to induce acute prolongation of various electrocardiographic time intervals supporting the evidence of a potential arrhythmogenic effect of ethanol [22]. We observed at $6 \mathrm{~h}$ and
$24 \mathrm{~h}$ following ethanol injection, increased corrected QT-interval, a biomarker for ventricular tachyarrhythmia, which occurred while the heart rate was normal, suggesting that the ventricular repolarization time had lengthened. When the movement of ions across the channels is disturbed, ventricular repolarization is prolonged, resulting in prolongation of the QT-interval. Despite the apparent significance of ethanol interaction with the ion channels on cardiomyocytes membranes, the data published so far describing the effect of ethanol on ionic currents of cardiac cells are scarce. Some authors reported an alteration of calcium homeostasis, especially an up-regulation of cardiac L-type calcium channel in mice exposed to acute alcohol consumption [23]. However, our data showed that following acute ethanol administration both mRNA and protein expression of L-type calcium channel, SERCA-2 and $\mathrm{Na}^{+} / \mathrm{K}^{+}$-ATPase remained unchanged.

Excessive consumption of alcohol over a short period of time (binge drinking) induces a systemic inflammatory reaction [24], which might lead to alcohol-induced myocardial inflammation. Over expression of TNF- $\alpha$ in the myocardium contributes to cardiac dysfunction caused by systemic and local insults. In the present study down-regulation of TNF- $\alpha$ and inducible NOS accounts for the absence of inflammation, which is also supported by our H\&E staining showing no sign of myocardial inflammation. It has been shown in monocytes and macrophages that likely acute alcohol exposure directly increases transcription of heat shock protein 70, which in turn could repress $\mathrm{TNF}-\alpha$ gene expression [25]. Taken together, decreased LV contractility of the donor heart in the present study seems to be specific to ethanol-induced myocardial injury than inflammation. Moreover, impaired myocardial contractility after transplantation also bolsters this mechanism. 
Accumulation of reactive oxygen species in response to ethanol exposure is believed to play an important role. Ethanol or acetaldehyde, the primary metabolic product of ethanol, is known to trigger both oxidative stress and apoptosis [26]. This is also supported by our experimental findings that anti-oxidant enzyme, SOD-1 one of first line defense enzymes mRNA level was upregulated at $24 \mathrm{~h}$ and protein level after $6 \mathrm{~h}$ and $24 \mathrm{~h}$ following acute ethanol exposure. Additionally, both mRNA and protein levels for GPx-4 was increased $24 \mathrm{~h}$ after ethanol administration, depicting initiation of oxidative stress. In the present study, we evaluated two antioxidant enzymes, which do not exclude the involvement of other enzymes or non-enzymatic antioxidants following acute ethanol exposure. Moreover, it is known that both in vivo and in vitro, oxidative stress activates latent resident myocardial matrix MMPs [27]. We showed in this study that MMP-9 mRNA-expression was upregulated at $6 \mathrm{~h}$ and $24 \mathrm{~h}$ and protein level was increased after $24 \mathrm{~h}$ following ethanol administration, which may indicate an increase in oxidative stress. In addition, we showed in this study that acute ethanol exposure resulted in formation of DNA-strand breaks as evidenced by our positive TUNEL staining. Recently, mitochondrial dysfunction also received some attention in the onset of alcoholic complications [28]. Data from our current study revealed that $24 \mathrm{~h}$ following acute ethanol administration, there was increased both mRNA and protein expression of myocardial cytochrome-c oxidase, a terminal enzyme in the mitochondrial electron transport chain. This suggests a role of the mitochondrial death pathway in ethanol-induced apoptosis. A previous work showed in an in vitro model that isolated cardiomyocytes treated with high-dose of ethanol induced oxidative stress and apoptosis [29]. Consistent also with our data, Guo et al. showed that in mice acute ethanol exposure-induced myocardial dysfunction is associated with mitochondrial damage and apoptosis, supporting an essential role of acetaldehyde and mitochondrial dysfunction in ethanol-elicit alcoholic myopathic alteration [30]. Moreover, ethanol exposure impairs glucose homeostasis. In humans, ethanol consumption is associated with increased circulating glucose concentration, glucose intolerance, and glucose homeostasis [31]. It has been reported that short-term ethanol treatment in rats leads to glucose intolerance similar to that reported in humans [32]. Recent data suggested that chronic alcohol consumption could not only result in glucose intolerance in hepatocytes and skeletal muscles but could also lead to alcoholic cardiomyopathy [33]. In this present study we showed that acute alcohol administration resulted in elevated plasma glucose levels, which peaked at $1 \mathrm{~h}$, time corresponding to decreased cardiac contractility and declined at $6 \mathrm{~h}$ and $24 \mathrm{~h}$, times corresponding to normal systolic function of donor hearts.

The use of hearts from donors with a history of "alcohol abuse" remains uncertain [34]. We sought to explore if acute alcohol abuse associated with a potential heart transplant donor can influence recipient graft function because the transplantation of these hearts may unmask abnormalities that may manifest after ischemia/reperfusion injury. The underlying pathophysiological mechanisms of ischemia/reperfusion injury include oxidative stress which could induce apoptosis and mitochondrial dysfunction, changes in calcium homeostatasis, inflammation, osmotic swelling, metabolic modulation, rapid restoration of physiologic $\mathrm{pH}[35,36]$. In a rat model of heart transplantation, donor rats received ethanol $6 \mathrm{~h}$ or $24 \mathrm{~h}$ before explantation, these time points were selected to be relevant to clinical cardiac transplantation and the measurements were done $1 \mathrm{~h}$ or $24 \mathrm{~h}$ after transplantation. Although the explanted heart function was recovered from ethanol-induced systolic dysfunction, we showed impaired con- tractile function $1 \mathrm{~h}$ and also unexpectedly $24 \mathrm{~h}$ after heart transplantation. In our laboratory, we previously showed in canine orthotopic heart transplantation [37] and cardiopulmonary bypass models of global ischemia/reperfusion [38] and in a rat model of transplantation-induced ischemia/reperfusion injury [14] decreased LV contractility. However, we and others have already demonstrated that $24 \mathrm{~h}$ after transplantation systolic and diastolic function return to normal $[39,40]$. In the present study persistence of graft dysfunction $24 \mathrm{~h}$ after transplantation needs to be considered during heart transplantation when hearts from donor with alcohol abuse are used. Systolic LV dysfunction is relatively common in even asymptomatic alcoholics, but whether diastolic function is also altered is much less well-studied [41]. Care must be taken because in the present study our data additionally showed that acute alcohol abuse affects diastolic function of donor hearts and the myocardial alterations are at the cellular level. Moreover, in the recipients LV diastolic dysfunction was still present after transplantation. The possible explanation for normal contractile function after $6 \mathrm{~h}$ and $24 \mathrm{~h}$ following ethanol exposure and depressed systolic and diastolic function after heart transplantation could in part involve the alteration of SOD-1, GPx-4, MMP-9, cytochrome-c oxidase both at mRNA and protein levels due to ethanol exposure. Moreover the increased protein expression levels were still present $24 \mathrm{~h}$ after heart transplantation. The changes in calcium homeostasis and the inflammatory process do not seem to play an important role. One hour and also $24 \mathrm{~h}$ after heart transplantation, in which donors received ethanol $24 \mathrm{~h}$ prior to explantation, an increase in myocardial oxidative stress has been shown as evidenced by elevated myocardial TBARS levels. Thus, all these mentioned events may be further aggravated by ischemia/reperfusion injury with subsequent development of graft dysfunction.

\section{Conclusions}

In summary, in a model of potential organ donor, we demonstrated that after $1 \mathrm{~h}$ ethanol induced myocardial contractile dysfunction and elevated plasma glucose concentration. Although these parameters returned to near normal levels $6 \mathrm{~h}$ and $24 \mathrm{~h}$ after ethanol administration, morphological and molecular changes at the level of myocardium began to appear only at $24 \mathrm{~h}$. Moreover, diastolic dysfunction is also observed following acute ethanol administration and sustained during $24 \mathrm{~h}$. One hour and unexpectedly $24 \mathrm{~h}$ after heart transplantation, in which donors received ethanol $6 \mathrm{~h}$ or $24 \mathrm{~h}$ prior to explantation, decreased myocardial contractility and relaxation were observed even though the global contractile function of the donor hearts recovers $6 \mathrm{~h}$ after ethanol-administration. Oxidative stress, apoptosis, and mitochondrial dysfunction could predispose the donor hearts pump function in recipient to increased myocardial susceptibility to ischemia/reperfusion injury after transplantation. Further study is warranted to unveil the impact of acute-onchronic alcohol ingestion on the outcome of ischemia/reperfusion injury after heart transplantation.

The rat model of heterotopic heart transplantation was selected to be a suitable model to evaluate global ischemia/reperfusion injury. However, this model has certain limitations. In particular, the left ventricle beats in an unloaded condition (e.g. the ventricles are perfused via the coronary circulation, but they do not eject) which on one hand allows a faster recovery after ischemia/ reperfusion and on the other hand leads to a time-dependent mechanical deterioration and atrophy. Nevertheless, in detailed characterization studies with this model, it has been shown that major deterioration does not occur until at least $24 \mathrm{~h}$ after 
implantation [39]. Even assessment of long-term effects in the present model was not possible, early graft dysfunction is the main determinant of long-term outcome following transplantation. Therefore, evaluation of graft function on early phase after heart transplantation has clinical significance and importance. Additionally, even though a chronic alcohol ingestion rat model can have more clinically significant scenario, it has been shown that the rat is not very suitable model for studying "alcoholic cardiomyopathy" [42].

\section{References}

1. O'Keefe JH, Bybee KA, Lavie CJ (2007) Alcohol and cardiovascular health: the razor-sharp double-edged sword. J Am Coll Cardiol 50: 1009-1014.

2. Ettinger PO, Wu CF, De La Cruz C, Jr., Weisse AB, Ahmed SS, et al. (1978) Arrhythmias and the "Holiday Heart": alcohol-associated cardiac rhythm disorders. Am Heart J 95: 555-562.

3. Spies CD, Sander M, Stangl K, Fernandez-Sola J, Preedy VR, et al. (2001) Effects of alcohol on the heart. Curr Opin Crit Care 7: 337-343.

4. Ando H, Abe H, Hisanou R (1993) Ethanol-induced myocardial ischemia: close relation between blood acetaldehyde level and myocardial ischemia. Clin Cardiol 16: 443-446.

5. Molina PE, Hoek JB, Nelson S, Guidot DM, Lang CH, et al. (2003) Mechanisms of alcohol-induced tissue injury. Alcohol Clin Exp Res 27: 563-575.

6. Thomas AP, Rozanski DJ, Renard DC, Rubin E (1994) Effects of ethanol on the contractile function of the heart: a review. Alcohol Clin Exp Res 18: 121-131.

7. Hannuksela ML, Liisanantti MK, Savolainen MJ (2002) Effect of alcohol on lipids and lipoproteins in relation to atherosclerosis. Crit Rev Clin Lab Sci 39: 225-283.

8. Freimark D, Aleksic I, Trento A, Takkenberg JJ, Valenza M, et al. (1996) Hearts from donors with chronic alcohol use: a possible risk factor for death after heart transplantation. J Heart Lung Transplant 15: 150-159.

9. Hantson P, Mahieu P (1999) Organ donation after fatal poisoning. Ojm 92: 415-418.

10. Hepp A, Schier H, Kochsiek K (1984) Comparative haemodynamic studies on the acute cardiac effects of alcohol in the rat and guinea pig. Eur Heart J 5: 8589.

11. Ma H, Li J, Gao F, Ren J (2009) Aldehyde dehydrogenase 2 ameliorates acute cardiac toxicity of ethanol: role of protein phosphatase and forkhead transcription factor. J Am Coll Cardiol 54: 2187-2196.

12. Kmecova J, Klimas J (2010) Heart rate correction of the QT duration in rats. Eur J Pharmacol 641: 187-192.

13. Pacher P, Nagayama T, Mukhopadhyay P, Batkai S, Kass DA (2008) Measurement of cardiac function using pressure-volume conductance catheter technique in mice and rats. Nat Protoc 3: 1422-1434.

14. Szabo G, Bahrle S, Stumpf N, Sonnenberg K, Szabo EE, et al. (2002) Poly(ADPRibose) polymerase inhibition reduces reperfusion injury after heart transplantation. Circ Res 90: 100-106.

15. Chang G, Astrachan BM (1988) The emergency department surveillance of alcohol intoxication after motor vehicle accidents. Jama 260: 2533-2536.

16. Reilly ME, Mantle D, Richardson PJ, Salisbury J, Jones J, et al. (1997) Studies on the time-course of ethanol's acute effects on skeletal muscle protein synthesis: comparison with acute changes in proteolytic activity. Alcohol Clin Exp Res 21: 792-798.

17. Wang GW, Guo Y, Vondriska TM, Zhang J, Zhang S, et al. (2008) Acrolein consumption exacerbates myocardial ischemic injury and blocks nitric oxideinduced PKCepsilon signaling and cardioprotection. J Mol Cell Cardiol 44: 1016-1022.

18. Ma H, Guo R, Yu L, Zhang Y, Ren J (2011) Aldehyde dehydrogenase 2 (ALDH2) rescues myocardial ischaemia/reperfusion injury: role of autophagy paradox and toxic aldehyde. Eur Heart J 32: 1025-1038.

19. Lang F, Ritter M, Volkl H, Haussinger D (1993) The biological significance of cell volume. Ren Physiol Biochem 16: 48-65.

20. Potapov EV, Ivanitskaia EA, Loebe M, Mockel M, Muller C, et al. (2001) Value of cardiac troponin I and $\mathrm{T}$ for selection of heart donors and as predictors of early graft failure. Transplantation 71: 1394-1400.

21. Patel VB, Ajmal R, Sherwood RA, Sullivan A, Richardson PJ, et al. (2001) Cardioprotective effect of propranolol from alcohol-induced heart muscle damage as assessed by plasma cardiac troponin-t. Alcohol Clin Exp Res 25: 882-889.

\section{Acknowledgments}

The expert technical assistance of Patricia Kraft, Karin Sonnenberg, Lutz Hoffmann and Nadine Weiberg is gratefully acknowledged. The authors thank Alice Lehner for her help with histological studies and Hermine Azadeh Harrison for critically reading the manuscript.

\section{Author Contributions}

Conceived and designed the experiments: SK GS. Performed the experiments: S. Li SK S. Loganathan TR GV. Analyzed the data: S. Li SK KH AW EB PH YZ LT SP GV GS. Contributed reagents/materials/ analysis tools: MK GS. Wrote the paper: SK S. Li TR GS.

22. Aasebo W, Erikssen J, Jonsbu J, Stavem K (2007) ECG changes in patients with acute ethanol intoxication. Scand Cardiovasc J 41: 79-84.

23. Guppy LJ, Littleton JM (1994) The time course of up-regulation and downregulation of dihydropyridine binding sites during the development of physical dependence on ethanol. Proc West Pharmacol Soc 37: 77-80.

24. Goral J, Karavitis J, Kovacs EJ (2008) Exposure-dependent effects of ethanol on the innate immune system. Alcohol 42: 237-247.

25. Mandrekar P, Catalano D, Jeliazkova V, Kodys K (2008) Alcohol exposure regulates heat shock transcription factor binding and heat shock proteins 70 and 90 in monocytes and macrophages: implication for TNF-alpha regulation. J Leukoc Biol 84: 1335-1345.

26. Patel VB, Why HJ, Richardson PJ, Preedy VR (1997) The effects of alcohol on the heart. Adverse Drug React Toxicol Rev 16: 15-43.

27. Cox MJ, Hawkins UA, Hoit BD, Tyagi SC (2004) Attenuation of oxidative stress and remodeling by cardiac inhibitor of metalloproteinase protein transfer. Circulation 109: 2123-2128.

28. Hajnoczky G, Buzas CJ, Pacher P, Hoek JB, Rubin E (2005) Alcohol and mitochondria in cardiac apoptosis: mechanisms and visualization. Alcohol Clin Exp Res 29: 693-701.

29. Guan Z, Lui CY, Morkin E, Bahl JJ (2004) Oxidative stress and apoptosis in cardiomyocyte induced by high-dose alcohol. J Cardiovasc Pharmacol 44: 696702.

30. Guo R, Ren J (2010) Alcohol dehydrogenase accentuates ethanol-induced myocardial dysfunction and mitochondrial damage in mice: role of mitochondrial death pathway. PLoS One 5: e8757.

31. Forman DT (1988) The effect of ethanol and its metabolites on carbohydrate, protein, and lipid metabolism. Ann Clin Lab Sci 18: 181-189.

32. Risinger FO, Cunningham CL (1992) Genetic differences in ethanol-induced hyperglycemia and conditioned taste aversion. Life Sci 50: PL113-118.

33. Limin T, Hou X, Liu J, Zhang X, Sun N, et al. (2009) Chronic ethanol consumption resulting in the downregulation of insulin receptor-beta subunit, insulin receptor substrate-1, and glucose transporter 4 expression in rat cardiac muscles. Alcohol 43: 51-58.

34. Costanzo MR, Dipchand A, Starling R, Anderson A, Chan M, et al. (2010) The International Society of Heart and Lung Transplantation Guidelines for the care of heart transplant recipients. J Heart Lung Transplant 29: 914-956.

35. Buja LM (2005) Myocardial ischemia and reperfusion injury. Cardiovasc Pathol 14: $170-175$.

36. Moens AL, Claeys MJ, Timmermans JP, Vrints CJ (2005) Myocardial ischemia/ reperfusion-injury, a clinical view on a complex pathophysiological process. Int J Cardiol 100: 179-190.

37. Szabo G, Soos P, Heger U, Flechtenmacher C, Bahrle S, et al. (2005) Poly(ADPribose) polymerase inhibition attenuates biventricular reperfusion injury after orthotopic heart transplantation. Eur J Cardiothorac Surg 27: 226-234.

38. Korkmaz S, Radovits T, Barnucz E, Hirschberg K, Neugebauer P, et al. (2009) Pharmacological activation of soluble guanylate cyclase protects the heart against ischemic injury. Circulation 120: 677-686.

39. Galinanes M, Hearse DJ (1991) Metabolic, functional, and histologic characterization of the heterotopically transplanted rat heart when used as a model for the study of long-term recovery from global ischemia. J Heart Lung Transplant 10: 79-91.

40. Szabo G, Bahrle S, Batkai S, Stumpf N, Dengler TJ, et al. (1998) L-arginine: effect on reperfusion injury after heart transplantation. World J Surg 22: 791797; discussion 797-798.

41. Kupari M, Koskinen P, Suokas A, Ventila M (1990) Left ventricular filling impairment in asymptomatic chronic alcoholics. Am J Cardiol 66: 1473-1477.

42. Hepp A, Rudolph T, Kochsiek K (1984) Is the rat a suitable model for studying alcoholic cardiomyopathy? Hemodynamic studies at various stages of chronic alcohol ingestion. Basic Res Cardiol 79: 230-237. 